Discussion Papers in Economics

\title{
Sequential lending with dynamic joint liability in micro-finance
}

Shyamlal Chowdhury, Prabal Roy Chowdhury and Kunal Sengupta

August 2014

Discussion Paper 14-07

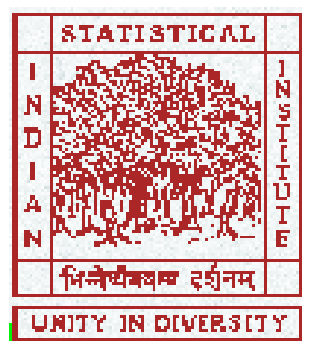

Indian Statistical Institute, Delhi

Economics and Planning Unit

7, S. J. S. Sansanwal Marg, New Delhi 110016, India 


\title{
Sequential lending with dynamic joint liability in micro-finance
}

\author{
Shyamal Chowdhury (University of Sydney) \\ Prabal Roy Chowdhury (Indian Statistical Institute) \\ Kunal Sengupta (University of Sydney)
}

\begin{abstract}
This paper develops a theory of sequential lending in groups in micro-finance that centers on the notion of dynamic incentives, in particular the simple idea that default incentives should be relatively uniformly distributed across time. In a framework that allows project returns to accrue over time (rather than at a single point), as well as strategic default, we show that sequential lending can help resolve problems arising out of coordinated default, thus improving project efficiency vis-a-vis individual lending. Inter alia, we also provide a justification for the use of frequent repayment schemes, as well as demonstrate that, depending on how it is manifested, social capital has implications for project efficiency and borrower default. We then examine the optimal choices for the MFI, demonstrating that the MFI opts for higher project sizes under group lending with limited collusion, and also provide a plausible explanation of the transition from group to individual lending.
\end{abstract}

Key words: Collusion; coordinated default; dynamic incentives; group-lending; microfinance; sequential financing; social capital; social sanctions.

JEL Classification Number: D7, D9, G2, O2.

*Address for Correspondence: Prabal Roy Chowdhury,

Economics and Planning Unit, Indian Statistical Institute, Delhi Center,

7 - S.J.S. Sansanwal Marg, New Delhi - 110016, INDIA.

E-mail: prabalrc1@gmail.com.

Fax: 91-11-41493981. 


\section{Introduction}

This article seeks to develop a simple theory of sequential lending in groups under micro-finance that centers on the notion of dynamic incentives, in particular the simple idea that default incentives should be relatively uniformly distributed across time. In a framework that allows project returns to accrue over time (rather than at a single point), as well as strategic default, we show that sequential lending can help resolve problems arising out of coordinated default, thus improving project efficiency vis-a-vis individual lending. Inter alia, we also provide a justification for the use of frequent repayment schemes, as well as demonstrate that, depending on how it is manifested, social capital has implications for project efficiency and borrower default. We then demonstrate that a socially motivated MFI opts for higher project sizes, and lends to a greater number of borrowers under group lending. Finally, we show that this framework provides a rich explanation of the transition from group to individual lending occurring over the last decade or so.

Sequential lending involves different group members being provided loans at different points of time and can trace its origin to ROSCAs (Besley et al., 1993). The institution of sequential lending has been widely adopted by many microfinance institutions (henceforth MFIs) in Asia and Africa, including Grameen I (and its replicators). ${ }^{1}$ While over the last decade or so there has been a move towards individual lending (e.g., Rai and Sjostrom, 2010), sequential lending still continues to be widely used. In India, for example, the Self Help Group (SHG) Linkage Program initiated by the National Bank of Agriculture and Rural Development provides loans in sequence (Aniket, 2009). ${ }^{2}$ Further, BRAC offers canonical Grameen I product in a number of African countries such as Liberia, Sierra Leone, Tanzania and Uganda. ${ }^{3}$ Even some European micro-finance programs follow sequential lending practices, e.g. the Kiutprogram for borrowers of Roma origin in Hungary and other European countries (Molnar, 2010), and the micro.bo. program in Bologna, Italy (Castri, 2010). It is therefore of interest to examine the reasons as to why sequential lending had been so widely used in the recent past, and still continues to be used in many cases. ${ }^{4}$

Turning to the formal model, we consider a framework where project returns are formulated in a dynamic fashion, as a stream of income accruing over a period of time. Further, project size is endogenous with project returns increasing in the level of initial investment. With borrowers being poor, they have to approach some MFI if they want to invest. Further, there is a problem of ex post moral hazard in that the borrowers can strategically default on their repayment obligations at any point of time (see Gine et al., 2011, for evidence on strategic default).

We begin by analyzing the benchmark case of individual lending, showing that the optimal repayment scheme has some interesting properties in that it involves immediate and frequent repayment (IFR for short), with the repayment starting early, and continuing at the maximal feasible rate until the MFI recoups its loan. Thus the optimal scheme demonstrates two features

\footnotetext{
${ }^{1}$ In Bangladesh, for example, our examination of the data collected by IFPRI in 1994 and used in Zeller et al. (1996) for 128 groups belonging to group-based credit programs of three MFIs in Bangladesh, ASA, BRAC and RDRS, shows that sequential lending was one of the features common to all three MFIs.

${ }^{2}$ The mechanism is described in details in Aniket (2006). The SHG-linkage program in India has grown rapidly, with the number of clients increasing from 38.02 million in 2006-07, to 54 million in 2008-09 (Srinivasan, 2009).

${ }^{3}$ Based on discussions with officials of BRAC International and field visits, in particular to BRAC Uganda.

${ }^{4}$ de de de de Quidt et al. (2012) report that out of 663 institutions that reported to Microfinance Information Exchange (MIX) in 2009, $12.2 \%$ of the lenders offered joint liability loans exclusively, and $57.9 \%$ offered some joint liability loans. Of course, this does not say anything as to whether the joint liability groups also used sequential lending or not.
} 
that appear to be 'near-universal' (Bauer et al., 2008), namely early and frequent repayment. Further, in the presence of either (a) risk-aversion, or (b) positive discounting, the optimal scheme may be 'gradual' in the sense that it asks for less than the maximal feasible payoff at every instant.

We find though that in case the moral hazard problem is severe (in a sense made formal later), then the efficient level of investment may not be attainable, even with IFR schemes. Given this, we then turn to the central question of this paper, namely whether group-lending with sequential financing can help improve efficiency.

In the group-lending context, we focus on the interaction between social sanctions and collusive possibilities. Social sanctions involve the borrowers who are adversely affected because of default, imposing some penalty on the defaulting borrower(s). While such sanctions can help prevent default, whether such sanctions are actually imposed or not, however depend on the extent of collusion among the borrowers.

We consider two scenarios, one where collusion is limited, and another where it is complete. In the first scenario, borrowers cannot make transfers to one another in a bid to avoid the imposition of social sanctions in case of default. Collusion in this case thus takes a limited form and simply involves not invoking the social sanction whenever all borrowers benefit from a coordinated default. Under the second scenario, we however allow borrowers to make transfers among one another. Complete collusion is modeled simply as the borrowers taking default/repayment decisions jointly, based on maximizing aggregate group payoff. Clearly, in case of a default, the social sanctions are never invoked.

Under the first scenario with limited borrower collusion, we find that sequential lending necessarily improves efficiency vis-a-vis individual lending (as long as group size is not too large). The basic intuition for this can be easily understood by considering a two member group. Let the first recipient default at a time when the second borrower is yet to receive her loan. Such a default will clearly adversely affect the second borrower, who obtains no loan, thus attracting the social sanctions. Next at the instant when the second borrower obtains her loan, the first borrower may have already repaid a substantial amount of her own loan because of IFR, and thus will be adversely affected if the second borrower defaults (because the lender will then liquidate both the projects). Consequently the first borrower will then impose the social sanction.

The possibility of limited collusion implies that the second borrower cannot obtain her loan too early in the cycle, otherwise there will be coordinated default by the borrowers. Furthermore, the second loan can not be too delayed either. This is because in that case when the first borrower completes her project, she will not impose the social sanction and this may then lead defaulting by the second borrower. It is this subtle interaction of dynamic incentives, in particular the interaction between sequential lending and IFR, that ensures that a higher project return can be implemented.

Note that our approach is based on two simple but robust ideas that (a) incentives to default are higher in case the amount to be repaid is higher, and (b) borrowers may collude in their default decisions, thus impairing the efficacy of social sanctions. Turning to the first idea, it leads to the intuition that default incentives must be relatively uniformly distributed across time, so that it is not too large at any single point. In the presence of limited borrower collusion, sequential lending serves to prevent such coordinated default by ensuring that the default incentives of the borrowers will not be completely aligned. In fact, under individual 
lending, even the IFR scheme is driven by the idea that default incentives should not become too large at any single instant.

We next examine the second scenario where there is complete collusion. Given that social sanctions have no bite in this situation we find, somewhat surprisingly, that the MFI can sustain more efficient projects compared to that under individual lending. The idea can again be illustrated most transparently for a two member group. While, at the start of the project, default payoffs involves a single project, the continuation payoff from not defaulting must take the potential income from both projects into account. Thus default incentives may not be too high early on. Next consider default incentives later on, after both borrowers have already obtained their loans. At this point, since the first project has already run its course for some time, and some repayment have already been made, the payoff from the first project would be higher if it is allowed to continue, rather than in case there is default. Consequently, default may not be too appealing from the standpoint of the group as well.

We find that even though social sanctions have no bite under complete collusion, dynamic incentives arising from the fact that default decisions take group payoffs into account, ensure that the maximal loan size under complete collusion exceeds that under individual lending.

The maximal sustainable loan size under complete collusion is however lower than that under limited collusion. The reason may not be obvious given that there are two countervailing forces at work here. While, the fact that social sanctions have no bite under complete collusion, makes loans harder to recover, the fact that default decisions take group payoffs into account, makes loans easier to recover. Why does the first effect necessarily dominate? This has to do with the fact that under limited collusion group size is taken to be large enough making social penalties an effective threat, whereas these have no bite under complete collusion.

We then consider the optimization problem facing a socially motivated MFI, i.e. one that cares for its borrowers, a natural assumption in this context and one that is well accepted in the literature. ${ }^{5}$ Solving for the optimization problem of such an MFI under both lending regimes, we find that both project size, as well as the number of borrowers served are higher under grouplending. Intuitively, with appropriately constructed schemes, default incentives are lower under group-lending. Since the MFI's payoffs are increasing in project size, this therefore implies that (a) the MFI optimally chooses a higher project size under group-lending, and (b) the MFI's marginal benefit from an additional borrower is higher under group lending, and consequently the number of borrowers served is also higher.

Finally, we use this framework to analyze a phenomenon that is not very well understood in the literature, namely the transition from group to individual lending discussed earlier. We use the framework developed here to argue that this shift can be attributed to the increase in MFI competition that was happening around the same time, in particular to three possible effects of such increased competition, namely (i) increased competition for donor funds, resulting in a higher opportunity cost of fund for the MFIs, (ii) an increase in the reservation utility of the borrowers arising out of a reduction in interest rates, and (iii) mission-drift, i.e. the MFIs becoming more profit-oriented. We show that all three will tend to make group-lending relatively more attractive for the MFI, thus providing a possible explanation of this transition.

The intuition has to do with the fact that default incentives are lower under group-lending.

\footnotetext{
${ }^{5}$ The United Nations Interagency Committee on Integrated Rural Development for Asia and the Pacific (1992) for example, mentions six defining characteristics of an NGO, one of them being 'highly socially motivated and committed'. See Besley and Ghatak $(2005,2006)$ for studies on incentive provision to socially motivated agents.
} 
Consider, for example, the effect of an increase in the opportunity costs of funds. This will tend to reduce project sizes, and consequently MFI payoffs, under individual, as well as group-lending. From the envelope theorem, the magnitude of this effect is exactly equal to the project size. Given that project sizes are larger under group lending, so will be the decline in profitability. Inter alia, we also analyze the effects of a ceiling on the interest rates being charged by the MFIs, as well as subsidized credit being provided to the MFIs.

The next section provides a brief review of the literature, whereas Section 3 describes the model, before going on to analyze the case of individual lending. Section 4 then examines a scenario with both IFR, as well as sequential lending, under limited, as well as complete collusion. Section 5 analyzes a scenario where the MFIs optimally decides on projects sizes, etc. Section 6 then uses this framework to analyze some questions of policy interest. Finally, Section 7 concludes. Some of the proofs can be found in the appendices.

\section{$2 \quad$ Related Literature}

We organize our literature review around three themes that this paper relates to, namely IFR, sequential lending and social capital.

\subsection{Immediate and Frequent Repayment (IFR)}

In Jain and Mansuri (2003), early repayment forces borrowers to borrow from friends/local moneylenders, thus tapping into the information possessed by these agents regarding the borrowers' credit worthiness.

In a couple of recent contributions, Fischer and Ghatak $(2010,2011)$ show that the presence of (i) a net continuation value in case of repayment (which may arise either because of contingent renewal, or from avoiding future punishment), and (ii) either present-biased preferences, or strict risk aversion by the borrowers (in the absence of savings instruments), make the incentive constraints at the earlier stages tighter, thus providing an explanation for frequent installments. Moreover, like in the present paper, they also make the point that smaller amounts may be less prone to diversion.

The two papers offers complementary insights though, being applicable under different scenarios. The present paper, for example, provides a theory that does not require either a net continuation value in case of repayment, or the borrowers to have either present-biased preferences, or strict risk aversion. Fisher and Ghatak $(2010,2011)$ on the other hand provide a theory that applies even when full repayment is possible in the very first period, a scenario that is not allowed for in the present paper. ${ }^{6}$

Albuquerque and Hopenhayn (2004) consider a repeated game theoretic model of lending with endogenous borrowing constraints where a firm requires working capital in every period. They find that the equilibrium contract involves paying no dividend in the initial years. While this result is reminiscent of our IFR result, it is driven by a different intuition, namely that doing so allows the firm to build up equity as quickly as possible, thus relaxing the borrowing constraint. Further, this policy is aimed at solving inefficiency with respect to working capital, rather than the scale of the project itself. Another related work is Shapiro (2012) who examines

\footnotetext{
${ }^{6}$ We would like to thank Maitreesh Ghatak and Dilip Mookherjee for encouraging us to clarify some of these issues.
} 
dynamic incentives in the presence of asymmetric information, but no enforcement problems. He shows that in all equilibria but one, even the most patient borrowers default with probability one.

Among empirical papers, Field and Pande (2008) find that a shift from a weekly to a monthly repayment scheme leads to no significant difference in either delay, or default. Field et al. (2010) however find that allowing for a grace period before repayment starts, increases default. Seen through the lens of the present paper, such grace periods would necessitate greater repayment later, thus pushing up the incentive to default later on. Feijenberg et al. (2011) use an experimental approach to argue that more frequent meetings (often associated with frequent repayment schemes), lead to lower default, possibly because of improvement in informal risk-sharing arising out of greater social interactions.

The present paper is thus complementary to this literature in that it provides an explanation of IFR that is not based on any of (i) asymmetric information, or (ii) a net continuation value in case of repayment and either present-biased preferences, or strict risk aversion by the borrowers, or (iii) social interactions.

\subsection{Sequential Lending}

The literature on sequential lending goes back to Varian (1990), who demonstrates that it provides incentives to high productivity borrowers to school low productivity types. Roy Chowdhury (2005) argues that sequential lending can encourage a high level of monitoring by the downstream borrowers. ${ }^{7}$ Aniket (2006) examines this issue using a framework with endogenously determined interest rates. Roy Chowdhury (2007) shows that in the presence of contingent renewal there is positive assortative matching, and, consequently, sequential lending allows the lender to test for the composition of a group relatively cheaply. Finally, while Aniket (2009) shows that sequential lending may widen access to less profitable projects, Sinn (2009) examines the role of sequential lending in the presence of ex post moral hazard problems. Ahlin and Waters (2011) also compare individual with joint liability lending, but in the presence of simultaneous group-lending.

In contrast to the literature, the present paper does not rely on either borrower monitoring, or testing for group composition, neither does it focus on borrowers' access to loans. Instead this paper unearths a role for sequential lending in preventing collusion, irrespective of whether it is limited, or complete.

Further, it examines the interaction between sequential lending and frequent repayment, an aspect that has thus far been ignored in the literature. In particular we show that there is a strong synergy between frequent repayment and sequential lending, to the extent that there can be scenarios where, working in isolation, neither can sustain any positive project size, but working together, they can sustain not just a positive project size, but even the efficient one.

\subsection{Social Capital}

Besley and Coate (1995) analyze the implications of social sanctions in a group-lending context, as well as emphasize the importance of ex post moral hazard problems. They find that depending on the magnitude of social capital, group-lending may, or may not lead to greater repayment as

\footnotetext{
${ }^{7}$ Conning (2005) makes the point that with simultaneous lending, the monitoring level of the borrowers are strategic complements.
} 
compared to individual lending. Laffont and Rey (2003) find that even with collusion, grouplending does better compared to individual lending. Other papers examining the issue of social capital include Aghion (1999), Bhole and Ogden (2010), Paal and Wiseman (2011) and de Quidt et al. (2012).

The experimental and empirical evidence on the efficacy of social capital in ensuring timely repayment is decidedly mixed. Abbink et al. (2006) in a lab experiment find that groups consisting of strangers do as well as self-selected groups. In a similar vein, Wydick (1999) using group lending data from Guatemala finds that friends do not make better group members. Ahlin and Townsend (2007) also find that proxies for social ties are correlated with weaker repayment performance in Thailand. In contrast, Karlan (2007), Wenner (1995) and Gomez and Santor (2003) all find that social capital is correlated with positive repayment performances. Feijenberg et al. (2011) also find that social interactions have a positive impact on repayment, though in the individual, rather than group-lending context.

In contrast to Besley and Coate (1995) and Aghion (1999), we explicitly allow for borrower collusion against the lender. Also, in contrast to Laffont and Rey (2003), Bhole and Ogden (2010), Paal and Wiseman (2011), and de Quidt et al. (2012) we analyze sequential, rather than simultaneous lending schemes. Further, unlike Bhole and Ogden (2010) and Paal and Wiseman (2011), we do not allow for repeated interactions but instead analyze a dynamic oneoff interaction. Finally, in contrast to both these papers, the magnitude of social sanctions is norm driven in our framework. We add to this literature by analyzing how social capital interacts with sequential lending, in particular how the nature of collusion affects repayment performance. In so doing this paper, along with Paal and Wiseman (2011), takes a step in reconciling the mixed results found in the empirical literature.

\section{The Model}

The framework is populated by a lender, namely an MFI, and a set of potential borrowers of size $n$. Each borrower has a project that requires a start-up capital of $k$, where $k$ is a choice variable and can take any non-negative value. Project returns accrue over time, starting at time 0 (say), so that a project of size $k$ yields a return of $F(k)$ at every $t \in[0,1] . F(k)$ is increasing, strictly concave and once differentiable in $k$, with $F(0)=0$. Moreover, $F(k)$ satisfies a version of the Inada condition, with $\lim _{k \rightarrow \infty} F^{\prime}(k)<1$. Project returns are observed by the lender.

We assume that neither the MFI, nor the borrowers discount the future and that all have linear utility functions defined over money. Denoting the opportunity cost of 1 unit of fund for the lender by $(1+c)$, where $c \geq 0$, the 'efficient' project size $k^{*}(c)$ is then obtained by maximizing $F(k)-k(1+c)$. Given strict concavity of $F(k)$, it follows that there exists a unique value of $k^{*}(c)$ that maximizes $F(k)-k(1+c)$. Since $F(0)=0$, it follows that $k^{*}(c)>0$ if and only if $F^{\prime}(0)>1+c$, with $F^{\prime}\left(k^{*}(c)\right)=1+c$ under this condition. We maintain this assumption throughout this paper. We also note that strict concavity of $F(k)$ implies that $F(k)-k(1+c)>0$ for all $0<k \leq k^{*}(c)$.

The borrowers have no investible fund. Thus, to implement a project of size $k$, they must borrow the amount $k$ from the MFI and agree to repay the lender according to some repayment schedule. In what follows, we assume that the lender charges an interest rate $r$ for his loan, $r \geq 0$, so that for any project of size $k$, the aggregate repayment must equal $k(1+r)$.

As in Besley and Coate (1995), a borrower is allowed to strategically default on her repay- 
ment obligation at any date $t .{ }^{8}$ In the event of such strategic default, the project is 'liquidated' with the borrower obtaining a private benefit of $(1-t) b(k)$ and the lender obtaining $(1-t) z(k)$, where $b(k), z(k) \geq 0$. Throughout, we maintain the following assumption.

\section{A.1.}

(i) $b(k)$ is increasing and once differentiable in $k$, with $b(0)=0$. Furthermore, for every $k>0$

$$
F(k)>b(k)+z(k) .
$$

(ii) For all $k \geq 0, \frac{b(k)}{F(k)}$ is non-decreasing in $k$.

A.1(i) implies that 'liquidation' is ex post inefficient. Our interest given A.1(i) will be to characterize outcomes that do not involve strategic default and liquidation. As will be clear shortly, the actual magnitude of $z(k)$ plays no role in the ensuing analysis and henceforth, we normalize its value to zero. On the other hand, A.1(ii) captures the intuitive notion that default incentives are non-decreasing in the project size $k$, and will be satisfied quite generally. In particular, since $F(k)$ is strictly concave, $\frac{b(k)}{F(k)}$ will be decreasing in $k$ if $b(k)$ is (weakly) convex. Moreover, if $b(k)=\gamma F(k)$, where $0<\gamma<1$, then $\frac{b(k)}{F(k)}$ is a constant function of $k$ and A.1(ii) is satisfied.

We note that the formulation of the default payoff adopted in this paper is quite general and encompasses many different scenarios.

One interpretation is that the default payoff $b(k)(1-t)$ is closely tied to the physical liquidation of the project, arising either directly out of liquidation by the MFI itself, or as the benefit that the borrower can garner for herself by overusing the asset just prior to defaulting at $t$ (with subsequent liquidation by the lender yielding a residual benefit of $(1-t) z(k)$ to the lender).

The default payoff however need not necessarily involve physical liquidation of assets, and can be interpreted more broadly. ${ }^{9}$ For instance, one can assume that if the borrower wants to default, she can hide the return $F(k)$ from the lender. In order to do this however, the borrower needs to incur a cost which is some fraction $1-\gamma$ of the actual output $F(k)$. Given this interpretation, the default payoff to the borrower can then be written as $\gamma F(k)(1-t) \cdot{ }^{10}$

Another possible interpretation is that, following a default, the MFI imposes some one-shot penalty on the borrower, say $p>0$. Such one shot penalties arise quite naturally, for example, in case the MFI's punishment strategies involve some form of social shaming. The borrower however continues to use the project technology without any further loss of efficiency, so that the default payoff is given by $F(k)(1-t)-p \cdot{ }^{11}$ Default may also lead to denial of future loans, or a defaulting borrower's credit history being wiped out. While such additional penalties would make default less attractive, and some implications of allowing for such default payoffs are

\footnotetext{
${ }^{8}$ There is also a large literature on ex ante moral hazard, e.g. Banerjee et al (1994), Bond and Rai (2009), Conning (1999), Ghatak and Guinnane (1999), and Stiglitz (1990), as well as adverse selection in micro-finance, e.g. Aghion and Gollier (2000), Ghatak (1999, 2000), Laffont and N'Guessan (2000), Laffont and Rey (2003), Sadoulet (2000), Rai and Sjostorm (2004), van Tassel (1999), and Varian (1990).

${ }^{9}$ We are thankful to two referees who suggested these alternative interpretations.

${ }^{10} \mathrm{~A}$ default payoff of $\gamma F(k)(1-t)$ can also arise in case the default penalty leads to some loss of efficiency, though not physical liquidation of the assets. Such loss of efficiency can arise in case (a) default leads to some loss of social capital following some form of public shaming, for example, public disclosure of such default, and (b) the project payoff is itself dependent on social capital.

${ }^{11}$ While this interpretation fits less obviously into the present framework, we shall later discuss the implications of adopting this alternative formulation of the default function under individual lending.
} 
analyzed in Fischer and Ghatak $(2010,2011)$, a full analysis is beyond the scope of this paper. In the rest of the paper, we thus use liquidation as a portmanteau term that allows for all the different interpretations that can be represented via the default function $b(k)(1-t)$.

\subsection{Individual Lending}

The case of individual lending forms a benchmark for the later analysis. This is also of independent interest since, as discussed in the introduction, some MFIs are either moving away from group loans, or do not impose any form of joint liability even though the loans may involve a group structure (ASA, for example, has some group loans without group guarantees, see, ASA (2008)).

We visualize the following scenario: at $t=0$, the MFI enters into a contract with a borrower that specifies the amount borrowed $k$, and a payment scheme $y(t, k), t \in[0,1]$, where $y(t, k)$ is the instantaneous non-negative payment at date $t$. Let $Y(t, k)=\int_{0}^{t} y(\tau, k) d \tau$ denote the aggregate payment that the borrower makes in the time interval $[0, t]$. Throughout, we assume that borrowers are protected by limited liability so that at each date $t$, the maximum payment that can be made to the lender is no more than the aggregate returns that accrue till date $t$, i.e. $Y(t, k) \leq t F(k)$ for every $t$. If the borrower accepts the contract, she immediately invests $k$ in the project and has to make payments according to the repayment schedule. If the borrower fails to meet her payment obligations at any date $t$, the project is liquidated.

A repayment schedule $y(t, k)$ is said to satisfy the no default (ND) condition if, for every $t \in[0,1]$,

$$
F(k)(1-t)-\int_{t}^{1} y(\tau, k) d \tau \geq b(k)(1-t) .
$$

Given $k$, and $y(t, k)$ for which the ND condition holds, the aggregate repayment received by the lender is given by $\int_{0}^{1} y(t, k) d t$.

For any $r$, we say that a lending scheme $\langle k, y(t, k)>$ is said to be $r$-feasible if it satisfies the ND condition and

$$
\int_{0}^{1} y(t, k) d t=k(1+r) .
$$

Note that if $r \geq c$, then equation (2) also ensures that the MFI makes non-negative profits on its loans.

Our plan in this section, as well as the following one, is to characterize the set of $r$-feasible project sizes $k$, taking the interest rate $r$ as given. In Sections 5-6, we then specify an objective function for the MFI and explicitly solve for the MFI's optimization problem.

We next define a simple class of contracts, where the loan amount is repaid in the shortest possible time.

DEFINITION 1. An immediate and frequent repayment scheme (henceforth IFR) corresponding to a project size $k$ and an interest rate $r$ is defined as

$$
y(t, k)= \begin{cases}F(k), & \text { if } 0<t \leq \frac{(1+r) k}{F(k)}, \\ 0, & \text { otherwise. }\end{cases}
$$

Our next result, Lemma 1, is analytically extremely convenient as it shows that, in the presence of risk neutrality and in the absence of discounting, one can, without loss of generality, restrict attention to such IFR contracts. 
Lemma 1. Under an individual lending arrangement, if a lending scheme $\langle k, y(t, k)\rangle$ is $r$-feasible, then the IFR scheme corresponding to the project size $k$ is also $r$-feasible.

Proof. We first observe that since the scheme $\langle k, y(t, k)>$ is $r$-feasible, it must satisfy the ND condition at $t=0$. But at $t=0$, the ND condition for any scheme is given simply by

$$
F(k)-k(1+r) \geq b(k)
$$

Next we consider the IFR scheme given $k$ and $r$. Under this scheme, the entire loan is repaid by $\tilde{t}$, where $\tilde{t}=\frac{k(1+r)}{F(k)}$. Consider $t<\tilde{t}$. Since, at any such date $\int_{t}^{1} y(\tau, k) d \tau=k(1+r)-F(k) t$, the ND constraint under an IFR can be re-written, using equation (1), as

$$
F(k)-k(1+r) \geq b(k)(1-t) .
$$

Clearly, under an IFR, the default incentives are decreasing over time. Thus, the ND constraints are satisfied for all $t$, if and only if the ND constraint at $t=0$, i.e. $F(k)-k(1+r) \geq b(k)$, is satisfied, which is true given (4).

The intuition as to why one can restrict attention to IFR schemes is simple. With a frequent repayment scheme, the installments are staggered, so that the amount to be repaid does not become very large at any one point, in particular as the project nears completion. While default incentives are largest at the very start of the project, i.e. at $t=0$, at this point continuation payoffs are also correspondingly higher. With any other repayment scheme, given that income accrues dynamically, time has to pass before the MFI can ask for repayment. At such an instant, however, the borrower has potentially less to gain from continuing with the project, so that default becomes more attractive.

We observe that Lemma 1 is consistent with Field et al (2010). It is also in line with Kurosaki and Khan (2009), who find that while, in Pakistan, several group-lending schemes failed in the late 1990s, there was a drastic decrease in default rates from early 2005, when contract designs were changed and involved more frequent repayment installments (and improved enforcement of contingent renewal).

For any $k$ which is $r$-feasible, let the payoff of a borrower be denoted $\pi(k, r)=F(k)-$ $k(1+r)$. Further, given $r \geq 0$, let $k^{0}(r)>0$ solve $\pi\left(k^{0}(r), r\right)=0$. Given our assumption that $\lim _{k \rightarrow \infty} F^{\prime}(k)<1$, for any $r \geq 0, k^{0}(r)$ is uniquely defined. Moreover, $\pi(k, r)>0$, if and only if $k<k^{0}(r)$.

We now introduce a notion that plays an important role in the development of our results.

Definition 2. For any $(k, r)$, with $\pi(k, r)>0$, define the average net default incentive,

$$
\phi(k, r)=\frac{b(k)-\pi(k, r)}{\pi(k, r)}=\frac{b(k)}{\pi(k, r)}-1 .
$$

Note that $b(k)-\pi(k, r)$ represents the net gain from defaulting at $t=0$. Thus $\phi(k, r)$ measures the net default incentive as a proportion of the net return, $\pi(k, r)$ at $t=0$. Clearly if the average net default incentive $\phi(k, r)$ is positive, a borrower with loan size $k$ will strictly prefer to default at $t=0$ and thus a loan of size of $k$ that promises the MFI an aggregate repayment of $k(1+r)$ cannot be sustained. 
In Appendix A we prove Lemma 2 which shows that for any $k_{1}, k_{2}$, such that $0<k_{2}<k_{1}<$ $k^{0}(r)$, we have $\phi\left(k_{2}, r\right)<\phi\left(k_{1}, r\right)$. Given Lemma 2, it follows that if a project of size $k>0$ is $r$-feasible, then a project of size $k^{\prime}<k$ is also $r$-feasible. The following proposition fully characterizes the set of project sizes that are $r$-feasible under individual lending.

Let $k^{I}(r)>0$ satisfy

$$
\phi\left(k^{I}(r), r\right)=0 .
$$

Note that $\phi(k, r) \rightarrow \infty$ as $k \rightarrow k^{0}(r)$. Since $\phi(k, r)$ is an increasing function of $k$ (Lemma $2), k^{I}(r)>0$ exists if and only if $\lim _{k \rightarrow 0} \phi(k, r)<0 .{ }^{12}$ Furthermore, Lemma 2 also ensures that $k^{I}(r)$ is uniquely defined.

Proposition 1. A project of positive size $k$ is $r$-feasible if and only $k$ is not too large, i.e. $0<k \leq k^{I}(r)$.

Proof. Now at $t=0$, under an IFR, the ND constraint is satisfied if and only if $k \leq k^{I}(r)$. Since the net default payoff from the IFR contract is decreasing in time (see the proof of Lemma 1 ), it then follows that for a project size $k$ to be $r$-feasible, it must be the case that $k \leq k^{I}(r)$.

Proposition 1 thus shows that given $r, k^{I}(r)$ is the maximum project size that is $r$-feasible.

Remark 1. A.1(ii) plays an important role in Proposition 1 as it ensures that $\phi(k, r)$ is an increasing function of $k$. This, in turn, ensures that the set of $r$-feasible project choices $k$ is a convex set, namely the interval $\left[0, k^{I}(r)\right]$. In the absence of A.1(ii), $k^{I}(r)$ needs to be defined as the supremum of all $k$ such that $\phi\left(k^{I}(r), r\right)=0$. Moreover, in such a case, it will not be true that if $k$ is $r$-feasible, then any $k^{\prime}<k$ is also $r$-feasible.

Remark 2. It might be of interest to note that in this set up, an IFR scheme does strictly better than an one shot repayment scheme in which the borrower repays the loan in a single installment. To see this, let $k_{O S R}^{I}(r)$ be the supremum of project sizes that is feasible under a one shot contract. Let $t_{O S R}$ be the date the repayment is made when the project size is $k_{O S R}^{I}(r)$. Since the borrower prefers not to default at $t_{O S R}$, we have $\left(1-t_{O S R}\right) b\left(k_{O S R}^{I}\right)+t_{O S R} F\left(k_{O S R}^{I}\right) \leq$ $\pi\left(k_{O S R}^{I}, r\right)$. By A.1 $(i)$, we have $F\left(k_{O S R}^{I}\right)>b\left(k_{O S R}^{I}\right)$ and thus $\pi\left(k_{O S R}^{I}, r\right)>b\left(k_{O S R}^{I}\right)$. This gives us $\phi\left(k_{O S R}^{I}, r\right)<0=\phi\left(k^{I}(r), r\right)$. From Lemma 2, we then have $k_{O S R}^{I}<k^{I}(r)$.

Remark 3. It is easy to extend the present formulation to allow for any possible dynamic incentive considerations that may arise if, in case of default, a borrower is denied loans in the future. Letting $V$ denote the utility loss to the borrower arising out of this possibility, it is straightforward to see that the no default condition in such a case can be written as $b(k, r)-V \leq$ $\pi(k, r)$ and the maximum project size $k$ will then satisfy $\phi(k, r)=\frac{V}{\pi(k, r)}$. As is clear, the presence of such considerations will reduce the net benefit of default and will allow larger project sizes to be $r$-feasible.

Remark 4. How does $k^{I}(r)$ compare with the efficient project size $k^{*}(c)$ ? It is easy to check that a necessary and sufficient condition for $k^{I}(r)$ to be strictly less than $k^{*}(c)$ is that $\phi\left(k^{*}(c), r\right)>0$. This condition is likely to hold, (a) higher the value of $b(k)$, (b) lower the value of $\pi(k, r)$ and (c) higher the interest rate $r$ (thus if $\phi\left(k^{*}(c), 0\right)>0$ then $k^{I}(r)<k^{*}(c)$ for all $r$ ).

\footnotetext{
${ }^{12}$ If $F^{\prime}(0)$ is finite, then $\lim _{k \rightarrow 0} \phi(k, r)<0$ iff $b^{\prime}(0)<F^{\prime}(0)-1-r$, and when $F^{\prime}(0)$ is infinite, the condition is $\lim _{k \rightarrow 0} \frac{b^{\prime}(k)}{F^{\prime}(k)}<1$.
} 
Proposition 1 essentially establishes two properties of feasible repayment schedules, namely that they involve (a) immediate and frequent repayment, as well as (b) front-loaded repayments. At this point it may be in order to examine how these two results hold up under alternative model specifications. We shall argue that while the property that feasible repayment schemes are front-loaded is qualified, the property that they involve immediate and frequent repayment goes through.

First, consider a scenario where the borrowers have strictly concave utility functions or have positive time discount factors. Under such a scenario, an IFR scheme, in general, will fail to be optimal. This is because alternative repayment schemes that shift some of the repayments to later instants (while keeping aggregate repayment unchanged) will be preferred by a borrower with diminishing marginal utility of income or who discounts the future. However, even in such a scenario, an optimal scheme must necessarily be characterized by 'gradual' repayments in that payments are made 'a little at a time' (Jain and Mansuri, 2003).

Next we consider the alternative default payoff function discussed earlier, where in case of default, there is a one shot penalty of $p>0$, but the borrower can continue her project without loss of efficiency. Under this specification, it is possible to show that the incentive to default is decreasing over time, so that it is sufficient to consider default incentives at $t=0$. This gives the result that a project size of $k$ can be sustained if and only if $p \geq k(1+r)$, so that an analogue of Proposition 1 will hold.

Proposition 1 tells us that if at $r=c, k^{I}(c)<k^{*}(c)$, then the efficient project size of $k^{*}(c)$ is not feasible under individual lending even when the lender makes zero profit. Strategic default considerations thus have serious efficiency implications. It is then natural to ask whether group contracts allows us to implement more 'efficient' project sizes. To this, we now turn.

\section{Group Lending and Social Capital}

We will consider group lending in the presence of dynamic joint liability. Under dynamic joint liability, the entire group is held responsible (and penalized) in case of default: first, if some borrowers default, then all existing projects are necessarily dissolved, and second, group members who are yet to receive their loans are denied any future loans. ${ }^{13}$

One important objective in examining group lending is to study the complex role played by social capital in ensuring repayment (Aghion and Morduch, 2005, pp. 123-125). Given that the empirical findings in this respect are quite mixed (as discussed earlier in Section 2.3), we seek to understand the trade-offs involved here. Without being too formal about it, let social capital capture the strength of the social ties present among the borrowers. ${ }^{14}$ We take the viewpoint that while such social ties may help sustain sanctions against defaulting borrowers, ${ }^{15}$ thus improving incentives for repayment, it can also encourage default in case close social ties in small village communities make social sanctions difficult to impose.

We begin by considering the positive aspects of social capital, namely the fact that a de-

\footnotetext{
${ }^{13}$ We shall later argue that while such a strict form of joint liability is convenient for expositional reasons, all our results hold even with a much weaker form of liability regime.

${ }^{14}$ Townsend (1994), Udry (1990) and Fafchamps and Lund (2003), among others, discuss various aspects of mutual insurance, risk pooling, gift giving and receiving, etc.

${ }^{15}$ Such social sanctions may involve exclusion from inputs, trade credit, social and religious events, day-to-day courtesies, communal assets, informal insurance networks, etc. See de Quidt et al (2012) for a discussion of possible alternative formulations of social capital.
} 
faulting member may be sanctioned by other members of the group. In the present paper such sanctions however, are assumed to be only imposed by those borrowers who are adversely affected following the default decision. These include borrowers who are yet to obtain a loan, and may also include borrowers who have obtained a loan, but have already repaid substantially, so that they would prefer not to default. We assume that each such affected member can invoke a penalty of $f$ on each of the deviating borrowers.

While we follow Besley and Coate (1993), among others, in imposing such social sanctions exogenously, the present formulation can perhaps be best interpreted as a reduced form approximation of a model where such penalties are imposed as part of optimal threat strategies. Such an interpretation makes sense in a scenario where, for example, social penalties involve exclusion from scarce community assets. In such cases social sanctions may involve no loss of efficiency, and would be easier to sustain as an equilibrium outcome. Sustaining such sanctions, however is much harder in situations where such sanctions are efficiency reducing, e.g. if it involves exclusion from mutual insurance networks. In such scenarios, one then needs to appeal to social preferences, in particular the presence of altruistic punishers (see, among others, Fehr and Schmidt (1999), Gintis et al. (2005), and the references therein) to sustain such sanctions.

We next discuss the negative aspects of social capital, i.e. the fact that "borrowers in a group-lending arrangement may collude against the bank and undermine the bank's ability to harness social collateral" (Aghion and Morduch, 2005, pp. 125). In a micro-finance context where borrowers communicate with one another, it seems natural to allow for some collusion. ${ }^{16}$ We argue that the observed differences in the impact of social capital on repayment performance can be traced to differences in the extent of collusion. We thus examine two scenarios with different degrees of collusion among the borrowers, limited and complete.

As discussed earlier, in the first scenario, borrowers cannot make transfers to each other and collusion thus simply involves not invoking the social sanction whenever all borrowers benefit from a coordinated default. Under complete collusion, we however allow borrowers to make such transfers among one another. Following Ghatak (2000), one can appeal to non-pecuniary forms of transfers, e.g. providing free labor services and the use of agricultural implements, to justify such side transfers. Furthermore, collusion is formalized very simply in that the group maximizes the aggregate payoff and thus decisions are made keeping the interest of the group in mind. Clearly, in case of complete collusion, social sanctions will never be imposed in case of default. ${ }^{17}$

While the diversity of the results in the empirical literature on social capital suggests that both of these scenarios are possible, the issue of when is collusion likely to be complete, i.e. whether side transfers are feasible, is a complex one. A more detailed analysis of this issue is, however, beyond the scope of the present paper.

\subsection{Two Stage Lending Schemes}

For the analysis in this section, we shall take the group size $n$ to be exogenously given. In what follows, we first study two stage group contracts in the presence of dynamic joint liability.

\footnotetext{
${ }^{16}$ One extreme example of such borrower collusion is from India where a woman defrauded MFIs to the tune of five hundred thousand rupees by setting up groups with the sole objective of appropriating the loan amount (Srinivasan, 2009).

${ }^{17}$ In the Grameen, for example, there seems to be some effort at fostering a group identity. At least three of the resolutions (12, 13 and 14), emphasize group payoff and joint welfare maximization. Source: http://www.grameen-info.org, accessed May 7, 2009.
} 
In two-stage group lending arrangements, the set of borrowers are divided into two groups, 1 and 2. The first group of borrowers, $(n-m)$ in size, receives a loan of $k$ each at $t^{1}=0$, while the remaining $m$ borrowers receive $k$ each at some later date $t^{2}>0$.

Let $y^{i}\left(t^{i}+\tau, k\right), \tau \in[0,1]$, denote a repayment schedule faced by a borrower in group $i, i=$ 1,2 , receiving her loan $k$ at date $t^{i}$. We represent such a scheme by $<n, m, t^{2}, k, y^{i}\left(t^{i} \tau, k\right)>$.

As before, we assume that there is limited liability on part of the borrowers so that the repayment obligations at any date can not exceed the aggregate returns generated till that date. We will further assume that the lender gets the same payoff from each individual loan, thus ruling out cross-subsidization by the lender. Finally, we assume that $y^{i}\left(t^{i}+\tau, k\right) \geq 0, i=1,2$ for all $\tau \in[0,1]$.

\subsection{Two Stage Lending Schemes without Side Payments}

In this sub-section we examine a scenario where side transfers are not possible, so that only 'limited collusion' can be sustained.

Fix any two stage lending scheme with repayment obligations given by $y^{i}\left(t^{i}+\tau, k\right)$. Let $P^{i}(t)$ denote the continuation payoff to a borrower in group $i$ at time $t$, assuming that no member of the group ever defaults on her loan. Similarly, given a default at $t$, let $D^{i}(t)$ denote the default payoff of a borrower in group $i$ at $t$, gross of social sanctions. Since default by any member leads to the liquidation of all existing projects, as well as denial of future loans, it follows that $D^{i}(t)$ depends only on $t$ and not on either the number, or the identity of those who default.

A borrower is said to be active at $t$, if he is yet to complete his project at that date. We assume that social sanctions at any date $t$ are imposed only by the members that are active at that date. Let $L(t)$ denote the set of active borrower at $t$ for whom $P^{i}(t) \geq D^{i}(t)$. The members of $L(t)$ are those who are adversely affected if default were to take place at $t$. Our assumption of limited collusion simply requires that a defaulting member be sanctioned only by the members of $L(t)$, i.e. by those who are adversely affected because of a default. Let $l(t)$ denote the size of $L(t)$ and $f>0$ denote the social sanction that can be imposed on a defaulting borrower. $^{18}$

A two stage lending scheme $<n, m, t^{2}, k, y^{i}\left(t^{i}+\tau, k\right)>$ satisfies the no default condition if, for all $t \in\left[0,1+t^{2}\right]$, and for an active borrower in group $i, i=1,2$,

$$
D^{i}(t)>P^{i}(t) \text { implies that } D^{i}(t)-l(t) f \leq P^{i}(t) .
$$

We should note that if $D^{i}(t) \leq P^{i}(t)$, then a borrower in group $i$ will prefer not to default even if no social sanctions are imposed on her and thus the no default condition will be automatically satisfied for such a borrower.

We say that a two-stage group arrangement with project size $k$ is $r$-feasible if there exists a repayment scheme $<y^{i}\left(t^{i}+\tau, k\right)>$ such that

- the no default condition in (7) is satisfied for all borrowers in group $i=1,2$, and

- for each borrower, the lender receives a payoff of $k(1+r)$.

\footnotetext{
${ }^{18}$ In an earlier version of the paper, $L(t)$ was defined as those set of borrowers who are strictly worse off because of a default decision. While the qualitative results under these two different assumptions are virtually identical, under the present formulation, the set of feasible projects will shown to be a closed set. This, in turn, ensures the existence of the optimal contracts studied in Section 5.
} 
Given $r \geq c$, the last condition ensures that the MFI breaks even.

Remark 5. Consider a group lending scheme with simultaneous lending, so that group members are all provided a loan amount $k$ at $t^{1}=0$. If $k>k^{I}(r)$, then $b(k)>\pi(k, r)$ and thus all borrowers will be better off defaulting on their loans and not invoking the social sanctions. Simultaneous group lending thus can not improve upon individual lending. For group lending to do better, lending then has to be sequential so that $t^{2}>0$.

To characterize the set of project sizes $k$ that are $r$-feasible under such a two stage arrangement, we begin by describing the immediate and frequent repayment (IFR) pertaining to each group. For any borrower $i$ who receives a loan of size $k$ at date $t^{i}$, this is given by

$$
y^{i}\left(t^{i}+\tau, k\right)= \begin{cases}F(k), & \text { if } 0<\tau \leq \frac{k(1+r)}{F(k)} \\ 0, & \text { otherwise }\end{cases}
$$

In Appendix B, we state and prove Lemma 3 that shows that in search of a feasible scheme, it is sufficient to restrict attention to IFR schemes. Thus Lemma 3, together with Remark 5 , establishes that a combination of sequential lending with IFR is the interesting class of institutions to examine.

Let $k^{L}(r)$ satisfy

$$
\phi\left(k^{L}(r), r\right)=1 .
$$

If $k^{I}(r)>0$, then it follows that $k^{L}(r)$ is uniquely defined (this is because of Lemma 2 and the fact that as $k$ increases to $k^{0}(r)>0$, where recall that $\pi\left(k^{0}(r), r\right)=0, \phi\left(k^{0}(r), r\right)$ goes to infinity.) Furthermore, $k^{L}(r)>k^{I}(r)$.

We now show that a necessary condition for a project size $k$ to be $r$-feasible, is that $k$ can not be more than $k^{L}(r)$.

First, note that in an IFR scheme, the default payoff for each borrower is decreasing in time. Thus, for the feasibility of such a scheme, it is sufficient to check the default incentives of the borrowers at exactly three dates: $t=\left\{0, t^{2}, 1\right\}$.

Now at $t=0$, if there is a default, this will adversely affect the remaining $m$ members as they would be denied any future loan. These borrowers will thus impose a penalty $f$ on any defaulting members. Thus, the maximum payoff that a defaulting member gets at $t=0$ is $b(k)-m f$. The continuation payoff for a borrower, however, is $\pi(k, r)$. Thus, the no default condition at $t=0$ is

$$
b(k)-m f \leq \pi(k, r) .
$$

Now consider the date $t^{2}$ at which the remaining $m$ borrowers receive their loans. Since $k>k^{I}(r)$, for the second group of members not to default, the first group of borrowers must impose the social sanction. Thus, as in (9), we must also have

$$
b(k)-(n-m) f \leq \pi(k, r) .
$$

Now for group 2 borrowers to be sanctioned by the first group, default at $t^{2}$ must adversely affect the borrowers in that group. Since the continuation payoff of the first group of borrowers at any date is at most $\pi(k, r)$, it follows that at $t^{2}$, for group 1 members to impose the sanction, a necessary condition is

$$
b(k)\left(1-t^{2}\right) \leq \pi(k, r) .
$$


Finally, at $t=1$, since the first group of borrowers would have completed their projects, no further sanctions will be forthcoming from this group. Thus, at $t=1$, the no default condition for a borrower in the second group is simply

$$
b(k) t^{2} \leq \pi(k, r)
$$

Adding equations (11) and (12), one obtains $b(k) \leq 2 \pi(k, r)$ as a necessary condition for $k$ to be $r$-feasible. This is equivalent to $\phi(k, r) \leq 1$, i.e. $k \leq k^{L}(r)$, thus establishing the claim.

It may be of interest to observe that $k^{L}(r)$ is independent of the magnitude of either $f$, or $n$. Thus, no matter how large either $f$ or $n$ is, project size larger than $k^{L}(r)$ can not be $r$-feasible. The next proposition establishes sufficient conditions on $f$ and $n$ for which project size $k^{L}(r)$ is in fact $r$-feasible.

Proposition 2. Assume that $b\left(k^{L}(r)\right)-\pi\left(k^{L}(r), r\right) \leq \frac{n f}{2} .{ }^{19}$ Then, under limited collusion and a two stage sequential lending scheme, a project of size $k$ is $r$-feasible if and only if $k \leq k^{L}(r)$.

Before we turn to proving this result, a couple of remarks might be useful.

Remark 6. Since for any $f>0$ (no matter how small), it is always possible to choose $n$ large enough such that the condition in Proposition 2 is satisfied, it follows that the conclusion of Proposition 2 holds as long as the choice of $n$ is unrestricted for the MFI.

Remark 7. It is of interest to examine the maximum $r$-feasible project size when $n f$ is small, so that $b\left(k^{L}(r)\right)-\pi\left(k^{L}(r), r\right)>\frac{n f}{2}$. It is straightforward to argue that the maximum $r$-feasible project size in that case is given by the maximum $\hat{k}$ for which $b(\hat{k})-\pi(\hat{k}, r)=\frac{n f}{2}$.

Proof of Proposition 2. Necessity is already proved.

To prove sufficiency, recall that $\frac{n f}{2} \geq\left[b\left(k^{L}(r)\right)-\pi\left(k^{L}(r), r\right)\right]$. Consider any $k>0$ such that $\phi(k, r) \leq 1$. We will show that there exists a two stage procedure under which $k$ is $r$-feasible. The interesting case to consider is when $k>k^{I}(r)$, since for $k \leq k^{I}(r)$, we can always choose a trivial two-stage group where all borrowers obtain their loans at the same time.

Let $t^{2} \in(0,1)$ satisfy

$$
t^{2} b(k)=\pi(k, r) .
$$

Since $k>k^{I}(r)$, it follows that $b(k)>\pi(k, r)$ and thus equation (13) has a unique solution $t^{2} \in(0,1)$.

Consider now a two stage procedure in which half of the $n$ borrowers receive their loan at $t=0$, while the remaining borrowers receive their loan at $t^{2}$. Every borrower has a repayment obligation given by the IFR corresponding to $(k, r)$.

Since $\frac{n f}{2} \geq\left[b\left(k^{L}(r)\right)-\pi\left(k^{L}(r), r\right)\right]$, and $b(k)-\pi(k, r)$ is increasing in $k$, it follows that at $k \leq k^{L}(r)$, equations (9) and (10) will both be satisfied as long as a defaulting member faces a sanction of $\frac{n f}{2}$.

Now, in the event of any default at $t=0$, sanctions will be imposed by the members who are yet to get get their loan as they will be adversely affected. Given (9), none of the borrowers receiving their loans at $t=0$ is thus going to default.

\footnotetext{
${ }^{19}$ Strictly speaking, this condition assumes that $n$ is even. When $n$ is odd, Proposition 2 holds whenever $b(k)-\pi(k, r) \leq \frac{(n-1) f}{2}$. In the sufficiency part, we then take the two sub-groups to be of size $n-1$, and $n+1$.
} 
Next consider $t=t^{2}$. We show that default at this date by any member in the second group must adversely affect all members in the first group who obtained their loan at $t=0$.

Two cases need to be considered:

Case (i). $t^{2} \geq \frac{k(1+r)}{F(k)}$ : In this case, at $t^{2}$, the first set of borrowers would have already repaid their loans, and therefore, their continuation payoff at this date equals $F(k)\left(1-t^{2}\right)$, which is strictly greater than $b(k)\left(1-t^{2}\right)$.

Case (ii). $t^{2}<\frac{k(1+r)}{F(k)}$ : In this case, the continuation no default payoff to any such borrower at $t^{2}$ is exactly $\pi(k, r)$. Now the default payoff at $t^{2}$ equals $b(k)\left(1-t^{2}\right)$ which, by equation (13), equals $b(k)-\pi(k, r)$. Since $\phi(k, r)=\frac{b(k)}{\pi(k, r)}-1 \leq 1$, it follows that $b(k)-\pi(k, r) \leq \pi(k, r)$. Thus, default at $t^{2}$ will adversely affect the first set of borrowers.

Thus in either case a default by any member of the second group adversely affects all members in the first group, and a defaulting borrower at this date will attract a social penalty of $f$ from all $n / 2$ borrowers in the first group. Thus, a group 2 member will not default at $t^{2}$.

Finally, consider $t=1$. If at this date, the second group has already repaid their loans, then their continuation payoff is $F(k) t^{2}$, which is strictly greater than $b(k) t^{2}$. On the other hand, if at $t=1$, the second set of borrowers are yet to pay back their loans, the continuation no default payoff to a borrower in this group is then exactly $\pi(k, r)$ while by defaulting she will get $b(k) t^{2}$. Using equation (13), it then follows that a borrower can not be strictly better off by defaulting.

Remark 8. As in the individual lending scheme, a sequential joint liability scheme does strictly better when coupled with IFR, rather than with an one shot repayment scheme. To see this, let $k^{m}$ be the maximum project size that is feasible with one shot repayment under limited collusion. Let $t^{m}$ be the date at which the second group of borrowers obtain their loans. First note that $t^{m} \leq \frac{1}{2}$. Otherwise, with $t^{m}>1 / 2$, at the time, when the second group of borrowers have to pay back, the first group of borrowers would have completed their projects by then, and hence default by the second group of borrowers will not attract any social sanction. Thus for any $k>k_{O S R}^{I}(r)$, borrowers in the second group will default. Now with $t^{m} \leq \frac{1}{2}$, and the fact that $t^{m} F\left(k^{m}\right) \geq k^{m}(1+r)$, we have $\frac{F\left(k^{m}\right)}{k^{m}(1+r)} \geq 2$. Now, $\phi\left(k^{L}(r), r\right)=1$ implies that $\frac{b\left(k^{L}(r)\right)}{\pi\left(k^{L}(r), r\right)}=2$. Since $b(k)<F(k)$, we thus have $\frac{F\left(k^{L}(r)\right)}{k^{L}(r)(1+r)}<2 \leq \frac{F\left(k^{m}\right)}{k^{m}(1+r)}$. Because of strict concavity of $F(k)$, it then follows that the $k^{m}$ must be strictly less than $k^{L}(r)$.

We end this section with a brief discussion of the role played by some of the assumptions made earlier in Proposition 2, namely that repayments are non-negative, that cross-subsidizing is not allowed and that dynamic joint liability holds.

In case negative repayments are possible (so that the MFI may pay the borrower), one can show that any project size that yields a strictly positive payoff to a borrower is feasible using schemes in which every borrower pays the MFI an amount $F(k)$ at every instant the project is active. When all borrowers have completed their projects, the MFI then returns the amount $F(k)-k(1+r)$ to each of the borrowers (the proof is available on request). Such a scheme however is problematic on several counts, e.g. since it requires the MFI to credibly commit to returning the amount due to the borrowers. Such schemes would also be ruled out in case there is free entry by the MFIs. This is because such schemes would require higher repayments by the borrowers at some point of time. But at such points they may be lured away by competing MFIs, causing such schemes to unravel. 
Proposition 2 also depends on the assumption that the lender is not allowed to crosssubsidize. Otherwise one can sustain a project size $k>k^{L}$, where both the borrowers obtain their loan simultaneously, but are required to repay different amounts. Then the borrower with the smaller repayment obligation may have little incentive to default herself and will therefore impose the social sanction in case of default by the other borrower. Now if the social sanction $f$ is large, then this threat will ensure that the other borrower does not default either. Of course, since such schemes treat borrowers asymmetrically, such contracts might be unacceptable to the borrowers. Further, in the presence of free entry by MFIs, such schemes would unravel as the borrowers with higher repayment obligations may be lured away by other MFIs.

Finally, note that in our framework, there is dynamic joint liability so that once any group member defaults, all projects are dissolved. Such a scheme would then be ex post inefficient if default were to take place in equilibrium. However, given the current set up (with no uncertainties in production), no borrower defaults along an equilibrium and therefore, the outcome is efficient ex ante, as well as ex post.

More importantly however, it can be shown that weaker forms of dynamic joint liability suffices for our analysis. Consider default at time $t$ by some borrower $j$, leading to borrower $j$ 's project being liquidated. Consider now a non-defaulting borrower. For such a borrower, assume instead a weaker form of joint liability under which such a borrower is allowed to continue with her project, but is subject to some penalty, e.g. that arising out of static joint liability (whereby non-defaulters are supposed to repay for the defaulters also). As long as the resultant continuation payoff is assumed to be less than the continuation payoff of this borrower in case there was no default, such a borrower will impose the social sanction on the defaulting borrower and Proposition 2 will continue to hold.

\subsection{Two Stage Group Lending Schemes with Side Payments}

We next study group lending schemes under 'complete collusion' that allows for side transfers among borrowers. We model this situation simply, by taking the group as a single entity that decides on its default decision, so as to maximize the aggregate group payoff.

The possibility of such side transfers have two opposing effects on the repayment incentives. On one hand, since the group acts as a single entity, it follows that social sanctions will never be invoked in this case. This effect, which is in line with Aghion and Morduch (2005, pp. 125), tends to increase default incentives. On the other hand, if the group decides to default early, it takes into account the possible loss such default will inflict on the members who will be denied loans in the future. This effect will then dampen default incentives of the group. Interestingly, however, we show that when $n$ is large such that the condition in Proposition 2 holds, the first effect always dominates and the maximum loan size that is feasible under complete collusion, is strictly less than $k^{L}(r)$. Even in this case, however, group lending schemes allow one to sustain higher loan sizes compared to that under individual lending.

As earlier, we denote a two-stage scheme by $<n, m, t^{2}, k, y^{i}\left(t^{i}+\tau, k\right)>$ in which $y^{i}\left(t^{i}+\tau, k\right) \geq$ 0 for $\tau \in[0,1]$ and $i=1,2$. Since side transfers are possible, to check for default incentives at any time $t$, one needs to compare the aggregate default payoff of the group and compare it with the non-default continuation payoff for the entire group. Since the social sanction will never be imposed by the group, the magnitude of $f$ does not have any effect on the repayment behavior of the group.

Given $<n, m, t^{2}, k, y^{i}\left(t^{i}+\tau, k\right)>$, let $P^{G}(t)$ denote the aggregate continuation payoff of the 
group assuming the group never defaults on its repayment obligations and $D^{G}(t)$ denote the group's aggregate default payoff at $t$.

A two-stage group arrangement $<n, m, t^{2}, k, y^{i}\left(t^{i}+\tau, k\right)>$ is said to be $r$-feasible if for all $t \in\left[0,1+t^{2}\right]$,

- $P^{G}(t) \geq D^{G}(t)$, and

- $\int_{\tau=0}^{1} y^{i}\left(t^{i}+\tau, k\right) d \tau=k(1+r)$ for $i=1,2$.

In such a case, we say that a project size $k$ is $r$-feasible under a two stage procedure with side transfers.

As in Lemma 3, it can be shown that in our search for an optimal two stage group lending arrangement, it is sufficient to restrict attention to IFR schemes. ${ }^{20}$

Given such a two stage scheme, to check for the no default conditions for the group, consider $t=0$, when the first group of borrowers, numbering $n-m$, receive their loans. If they default, the group will have an aggregate payoff of $(n-m) b(k)$ and thus the group will not default at $t=0$ if

$$
(n-m) b(k) \leq n \pi(k, r)
$$

Consider now the date $t^{2}$ at which the remaining $m$ borrowers receive their loans. Now if the group plans to default at this date, the net payoff is given by $(n-m) b(k)\left(1-t^{2}\right)+m b(k)$, whereas the maximal possible continuation payoff at $t^{2}$ in case of no default is $n \pi(k, r)$. A necessary condition for default to be unprofitable at $t^{2}$ is then $(n-m) b(k)\left(1-t^{2}\right)+m b(k) \leq n \pi(k, r)$ which can be re-written as

$$
n b(k)-t^{2}(n-m) b(k) \leq n \pi(k, r) .
$$

Dividing both sides of the preceding inequality by $n \pi(k, r)$ and recalling that $\phi(k, r)=$ $\frac{b(k)}{\pi(k, r)}-1$, we find, after rearranging terms that $\phi(k, r) \leq \frac{t^{2}(n-m) b(k)}{n \pi(k, r)}$. Whereas from (14) it follows that $\frac{(n-m) b(k)}{n \pi(k, r)} \leq 1$. Combining the preceding two inequalities, it then follows that

$$
\phi(k, r) \leq \frac{t^{2}(n-m) b(k)}{n \pi(k, r)} \leq t^{2}
$$

Finally, at $t=1$, the default payoff is $m b(k) t^{2}$, while the maximum continuation payoff for these $m$ borrowers is at most $m \pi(k, r)$. For default to be non-profitable at date $t=1$, it is therefore necessary that

$$
t^{2} \leq \frac{\pi(k, r)}{b(k)}
$$

Equations (16) and (17) thus imply that for feasibility of a scheme, $t^{2}$ should neither be too late (otherwise default incentives at $t=1$ are too large), nor too early (otherwise default incentives at $t=t^{2}$ are too large).

We now provide a set of necessary conditions for a project size $k$ to be $r$-feasible.

Let $k_{1}(r)$ and $k_{2}(r)$ satisfy

$$
\phi\left(k_{1}(r), r\right)=\frac{\pi\left(k_{1}(r), r\right)}{b\left(k_{1}(r)\right)} ; \quad \text { and } \quad \phi\left(k_{2}(r), r\right)=\frac{k_{2}(r)(1+r)}{F\left(k_{2}(r)\right)},
$$

\footnotetext{
${ }^{20}$ The proof is available upon request.
} 
respectively. In Lemma 4 (Appendix C), we show that (a) $k \leq k_{1}(r)$ if and only if $\phi(k, r) \leq$ $\frac{\phi(k, r)}{b(k)}$, and (b) $k \leq k_{2}(r)$ if and only if $\phi(k, r) \leq \frac{k(1+r)}{F(k)}$. Given Lemma 4, it then follows that $k_{1}(r)$ and $k_{2}(r)$ are well defined. Further, Lemma 4 also establishes that $k^{C}(r)$, defined as solving

$$
k^{C}(r)=\min \left\{k_{1}(r), k_{2}(r)\right\},
$$

is well defined and satisfy $\phi(k, r) \leq \min \left\{\frac{\pi(k, r)}{b(k)}, \frac{k(1+r)}{F(k)}\right\}$ if and only if $k \leq k^{C}(r)$.

Proposition 3 below shows that for any $n$, if a project of size $k$ is $r$-feasible, then $k \leq k^{C}(r)$. The converse, however, does not necessarily hold. The difficulty arises because with $n$ being a fixed integer and $\phi(k, r)$ taking values in a continuum, it may not be possible to satisfy the default constraints at all the dates using only finitely many group compositions. ${ }^{21}$ On the other hand, if the choice of $n$ was unrestricted, one can prove

Proposition 3. (a) [Necessity.] If a project of size $k$ is $r$-feasible, then the project size $k$ cannot be too large, i.e. $k \leq k^{C}(r)$.

(b) [Sufficiency.] If for a project of size $k$ it is the case that $k<k^{C}(r),{ }^{22}$ then there exists a group size $n$ and a group lending arrangement $<n, m, t^{2}>$ with immediate and frequent repayment for which a project of size $k$ is $r$-feasible.

Proof. Please see Appendix D.

Remark 9. Interestingly, for the complete collusion case, it is not necessarily the case that for every parameter configuration, the maximum $r$-feasible project size using a one shot repayment $i$ strictly less than $k^{C}(r)$. Consider for example, $F(k)=2 \sqrt{k}, b(k)=\frac{3 F(k)}{4}$. Then at $r=0$, it is possible to check that $k^{C}(0)$ solves $\phi(k, 0)=\frac{k}{F(k)}$ and equals $k=1$. The project size of $k=1$, however, is feasible using a one shot repayment scheme and a two stage arrangement in which $n=3, m=1$ and $t^{2}=\frac{1}{2}$.

We now use Propositions 1, 2 and 3, to compare the maximal loan size that can be sustained under various lending schemes and various scenarios. Recalling that $k^{I}(r)$ (respectively $k^{L}(r)$ ) is the maximum loan size that is $r$-feasible under individual lending (respectively two-stage lending with limited collusion), we have

Proposition 4. $k^{L}(r) \geq k^{C}(r) \geq k^{I}(r)$, with both inequalities being strict whenever $k^{I}(r)>0$.

Proof. Suppose that $k^{I}(r)>0$, then $k^{I}(r)$ is given by $\phi\left(k^{I}(r), r\right)=0$. Moreover, since $\phi\left(k^{C}(r), r\right)>0$ and $\phi(k, r)$ is increasing in $k$, we have $k^{C}(r)>k^{I}(r)$. From the definition of $k^{C}(r)$, we have $\phi\left(k^{C}(r), r\right) \leq \frac{k^{C}(r)\left(1+k^{C}(r)\right)}{F\left(k^{C}(r)\right)}<1=\phi\left(k^{L}(r), r\right)$ and thus by Lemma 2, $k^{C}(r)<k^{L}(r)$.

One interesting implication of the fact that $k^{C}(r)<k^{L}(r)$, is that if $\frac{n f}{2}$ is large enough so that Proposition 2 holds, then larger loan sizes can be sustained under group lending in case collusion is limited, a result that is consistent with Abbink et. al. (2006), Wydick (1999), Gine

\footnotetext{
${ }^{21}$ If one is willing to ignore the integer issue and treat $n$ as a continuous variable, then it is easy to modify the present proof of Proposition 3 and show that for any $n$, a project size $k$ is $r$-feasible if and only if $k \leq k^{C}(r)$.

${ }^{22}$ It might be of some interest to note that while $k^{C}(r)$ satisfies the necessary condition for feasibility, it is not possible to construct a two stage feasible arrangement if $\phi\left(k^{C}(r)\right.$ ) is an irrational number (see the proof of the Proposition 3).
} 
and Karlan (2010) and Ahlin and Townsend (2007), who find that the extent of default increases as cooperation among group members increase.

The intuition of this result is not straightforward as there are two countervailing forces at work here. First, the fact that social sanctions have no bite under complete collusion, makes loans harder to recover, the fact that default decisions take group payoffs into account, makes loans easier to recover. Which effect should dominate? Given any $f>0$, if $n$ is large enough, then aggregate social sanction can be made large enough to control default incentives under limited collusion. Since social penalties have no bite in the case of complete collusion, it then follows that a larger project size is $r$-feasible under limited collusion. On the other hand, if $n$ or $f$ are small, then aggregate social sanctioning has a very limited role in constraining default under limited collusion. Thus, in this case the first effect is negligible, so that a higher project size will be feasible under the complete collusion case.

\subsection{Sequential Lending and IFR: An Interactive Effect}

This subsection demonstrates that a scheme involving both sequential group lending and IFR amounts to more than the sum of its parts (i.e. IFR and sequential group lending), in the sense that the interaction between the two generates significant synergies in terms of the maximal $r$-feasible project size $k$.

Consider a situation where $1+b^{\prime}(0) \geq F^{\prime}(0)$ and $b^{\prime}(0) \geq 1$. Since, $\forall k, F(k)-k \leq b(k)$, it follows that $F(k)-k(1+r) \leq b(k)$, i.e. $k^{I}(r)=0$. It then follows from Proposition 1 that for every $r \geq 0$, no positive positive project size is $r$-feasible under individual lending with IFR. Next consider group lending with one shot repayment. Since $\lim _{k \rightarrow 0} F^{\prime}(k)=\lim _{k \rightarrow 0} \frac{F(k)}{k} \leq 2$, by strict concavity, $\frac{F(k)}{k}<2$ for $k>0$. Whereas by mimicking the argument in Remark 8 , it can be shown that irrespective of whether collusion is limited, or complete, for any $k$ to be feasible, it must be the case that $\frac{F(k)}{k(1+r)} \geq 2$, so that $\frac{F(k)}{k} \geq 2$. Thus no positive project size is $r$-feasible under either limited or complete collusion using one shot repayment contracts.

Consider now group lending using IFR. It can be shown that even under these conditions, a combination of these two can not only sustain a strictly positive project size, but possibly even the efficient one (see Propositions 2 and 3 for sufficient conditions, and the example below). Thus, there exists a broad range of parameter values for which neither IFR, nor sequential lending can sustain any positive project size by themselves, but a combination can sustain strictly positive amounts, thus establishing the existence of an interactive effect.

The following example illustrates. Let $F(k)=2\left(1-\frac{1}{e^{k}}\right), b(k)=\frac{F(k)}{2}$ and let $c=0 .{ }^{23}$ Clearly, $F^{\prime}(0)=2, b^{\prime}(0)=1$ and the efficient project size $k^{*}(0)$ is given by $e^{k^{*}(0)}=2$. Since $1+b^{\prime}(0)=F^{\prime}(0)$, it follows that $k^{I}(0)=0$. Moreover, since $F^{\prime}(0)=2$, it follows that $F(k) / k<2$ for all $k>0$. Hence, under limited collusion, and $r \geq 0$, no positive project size can be sustained when the lender uses sequential lending with one shot repayment. However, straightforward computations show that at $\phi\left(k^{*}(0), 0\right)<1$, and thus even the efficient project size, i.e. $k^{*}(0)$, is $r$-feasible under limited collusion with sequential lending scheme and IFR, as long as $\frac{n f}{2}$ is large enough. We next show that for this example, under complete collusion, a strictly positive level can be sustained when IFR and sequential lending is combined. This follows since $\phi(0,0)=\frac{b^{\prime}(0)}{F^{\prime}(0)-1}-1=0<\min \left\{\frac{k}{F(k)}, \frac{F(k)-k}{b(k)}\right\}_{k=0}=\min \left\{\frac{1}{F^{\prime}(0)}, \frac{F^{\prime}(0)-1}{b^{\prime}(0)}\right\}=\frac{1}{2}$, so that $k^{C}(0)>0$.

\footnotetext{
${ }^{23}$ The condition $c=0$ is made for ease of exposition alone. The example readily generalizes for strictly positive c.
} 
Note that this interactive effect not only provides a justification for considering a framework with both IFR and sequential group lending, further, this provides an explanation as to why, in reality, these two schemes often go together (in particular in case of those MFIs following the Grameen I mechanism). Moreover, this result has significant implications for empirical analysis as it suggests that any empirical work that examines either IFR or sequential lending in isolation, may significantly underestimate the power of sequential lending when combined with IFR.

\subsection{Multi-stage group lending schemes}

So far, our analysis has focussed on the situation where the lender is restricted to use group lending schemes with a limited number of stages, in particular schemes with two stages. While this appears to be a reasonable assumption empirically, it is of some interest to analyze how our results would be modified if the lender could use a group lending scheme with any number of stages. An earlier version of this paper had a detailed analysis of this issue. For completeness, we report the main findings here (the proofs are available on request).

First, in the case of limited collusion, we demonstrated that for any $f>0$, and $(k, r)$ such that $\pi(k, r)>0$, one can always choose $n$ large enough and a group lending scheme with $S$ stages, $S \geq 2$, in which the project size $k$ is $r$-feasible, demonstrating the power of sequential lending. The role of sequentiality is critical here, as the multi-stage nature of the scheme ensures that by the time the penultimate group of borrowers complete their projects, the final group of borrowers would be nearing the end of their own projects, and would have no incentive to default. Moreover, we find that the corresponding repayment scheme need not be too protracted. However, in an environment of complete collusion, the result is strikingly different. Indeed, we showed that for any given $(k, r)$, if a project size $k$ is $r$-feasible, then it must be that $\phi(k, r)$ is no more than $2 .{ }^{24}$ This result thus strengthens our intuition that complete collusion may have serious efficiency costs, even when rather complex schemes are allowed for.

We end this section by pointing out a connection between the group liability contract under complete collusion, and the contract under a scenario where there is only one single borrower who can, however, undertake more than one possible project. ${ }^{25}$ Assume that there are $n$ projects of the type that we have considered so far. Then, using our earlier analysis, it follows that if the MFI funds all the $n$ projects at $t=0$, then because of the incentive constraints, each project can be funded up to at most $k^{I}(r)$, i.e. the maximal $r$-feasible level under individual lending. The lender, however, can improve matters by financing only $n-m$ of the projects at $t=0$, and fund the remaining $m$ projects at some appropriate date later on, provided the borrower does not default on any of the existing projects. It is clear that this situation is isomorphic to the situation of group lending with complete collusion and thus from Proposition 3, such staggered financing will enable larger $k$ to be $r$-feasible for each of these projects.

\footnotetext{
${ }^{24}$ The exact statements and the proofs of these assertions are available upon request.

${ }^{25}$ We thank the editor of this journal and one of the reviewers for bringing this point to our attention.
} 


\section{Endogenous choice of $r, k$, the number of borrowers, group composition, and lending schemes}

In this section, we endogenously solve for several variables of interest, including the decision regarding whether to opt for individual, or group lending. We therefore consider a scenario where, under individual lending, the MFI decides on (i) the common loan size $k$ for each of the borrowers, (iii) the common rate of interest $r$ on each loan, and (iii) $N$, the number of borrowers that it wants to lend to. Further, in case of a group lending arrangement, the lender also has to decide on the number of groups, say $m$, as well as the size of each group, call it $n$, so that the total number of borrowers lent to, $M=m n .^{26}$

The objective behind developing this framework is to then use it to analyze several questions of interest and possible policy relevance in the next section. To keep the analysis tractable and simple, when considering the group lending regime, we will only consider a scenario with limited collusion. The task of characterizing the optimal contract in the case of complete collusion turns out to be significantly more complicated. And, although, it can be shown ${ }^{27}$ that the optimal project size is strictly greater than that obtained under individual lending, the comparative statics results are not easy to get.

Turning to the payoff function of the MFI, we allow for the possibility that the MFI is socially motivated, i.e. it cares for its borrowers, which is, as discussed earlier, a natural assumption in this context. Thus the gross utility of the MFI from lending to a single borrower, denoted $W(k, r ; c, \beta)=(r-c) k+\beta \pi(k, r)$, puts some weight on the borrower's payoff $\pi(k, r)$, where this weight is captured by $\beta \in[0,1)$. For $\beta=0$, we have a profit-maximizing MFI.

We will need the following assumption.

A.2. $F(k)-\mu b(k)$, is strictly concave in $k$, for all $\mu \in[0,1]$.

Note that A.2 is satisfied whenever either $b(k)$ is convex, or $b(k)=\gamma F(k), \gamma \in(0,1)$.

For ease of exposition, we begin by fixing $N$ under individual lending, as well as $n$ and $m$ under group-lending, and then characterize the optimal choices of $(k, r)$ under both regimes. These results are then used to develop a framework in which one can endogenously solve for $n, m$ and $N$.

\subsection{Individual lending}

Consider the MFI's optimization problem given the total number of borrowers, $N$. From symmetry, the optimization problem of the MFI simplifies to maximizing the per borrower payoff, i.e.

$$
\max _{k, r} W(k, r ; c, \beta)=[(r-c) k+\beta \pi(k, r)],
$$

subject to the no default constraint

$$
0 \geq \phi(k, r)
$$

obtained from Proposition $1 .^{28}$

\footnotetext{
${ }^{26}$ We are grateful to the Editor of this journal and to a referee who suggested that we study these questions.

${ }^{27} \mathrm{~A}$ proof is available upon request.

${ }^{28}$ Given our specification, it is possible that at the optimum, the per borrower profit of the MFI, i.e. $(r-c) k$, could be negative. To ensure that the MFI makes a non-negative profit for each borrower, one can introduce an additional constraint, namely $(r-c) k \geq 0$, in the MFI's optimization problem. This will not qualitatively affect any of our results.
} 
It is easy to check that at the optimal solution, denoted $\left(k_{I}, r_{I}\right)$, the no default constraint for a borrower must bind. Otherwise $\phi\left(k_{I}, r_{I}\right)>0$, since $\beta<1$, by increasing the interest rate slightly the MFI can increase its overall payoff, while ensuring that the ND constraint is satisfied. Thus given $\phi\left(k_{I}, r_{I}\right)=0$, it follows that $r k_{I}=F\left(k_{I}\right)-k_{I}-b\left(k_{I}\right)$. Substituting this into $W(k, r ; c, \beta)$, one can rewrite the per borrower payoff to the lender as

$$
F\left(k_{I}\right)-k_{I}(1+c)-(1-\beta) b\left(k_{I}\right) .
$$

The choice of $k_{I}$ then solves ${ }^{29}$

$$
F^{\prime}\left(k_{I}\right)-(1-\beta) b^{\prime}\left(k_{I}\right)=1+c .
$$

Finally, $r_{I}$ is given from the equation that $\phi\left(k_{I}, r_{I}\right)=0$, so that

$$
r_{I}=\frac{F\left(k_{I}\right)}{k_{I}}-1-\frac{b\left(k_{I}\right)}{k_{I}} .
$$

Note that $\left(k_{I}, r_{I}\right)$ is independent of $N$. Further, relating the optimal choice (when $r, k$ are both endogenous) with Proposition 1 , we find that $k_{I}=k^{I}\left(r_{I}\right)$, i.e. the MFI selects the maximal $r_{I^{-}}$feasible project size.

Let $W_{I}=W\left(k_{I}, r_{I} ; c, \beta\right)$ denote the per borrower payoff of the MFI under the optimal individual lending contract.

\subsection{Group lending with limited collusion}

Assume now that the MFI decides to lend to a group consisting of $n$ borrowers with limited collusion possibilities. Then, to maximize per borrower MFI payoff $W(k, r ; c, \beta)$, the lender will choose $\left(k_{g}, r_{g}\right)$ to maximize

$$
W(k, r ; c, \beta)=[(r-c) k+\beta \pi(k, r)],
$$

subject to the no default constraint obtained from Proposition 2, i.e.

$$
1 \geq \phi(k, r) .
$$

We shall focus on the case where $\frac{n_{g} f}{2} \geq b\left(k_{g}\right)-\pi\left(k_{g}, r_{g}\right)$, thus ensuring that $k_{g}$ is $r$-feasible (Remark 10 discusses the situation when this condition fails).

As before, the no default constraint binds at the optimum. Thus the choice of $\left(k_{g}, r_{g}\right)$ satisfies $\phi\left(k_{g}, r_{g}\right)=1$, which yields $\frac{b\left(k_{g}\right)}{\pi\left(k_{g}, r_{g}\right)}=2$. Using this condition, one can rewrite the per borrower objective function of the lender as

$$
F\left(k_{g}\right)-k_{g}(1+c)-(1-\beta) \frac{b\left(k_{g}\right)}{2} .
$$

The optimal $k_{g}$ is then obtained from

$$
F^{\prime}\left(k_{g}\right)-(1-\beta) \frac{b^{\prime}\left(k_{g}\right)}{2}=1+c
$$

\footnotetext{
${ }^{29}$ The second order condition is satisfied since for all $k, F^{\prime \prime}(k)-(1-\beta) b^{\prime \prime}(k)<0$ (from (A.2)).
} 
and $r_{g}$ can be solved using the fact that $\phi\left(k_{g}, r_{g}\right)=1$, or that

$$
r_{g}=\frac{F\left(k_{g}\right)}{k_{g}}-1-\frac{b\left(k_{g}\right)}{2 k_{g}} .
$$

Note that $\left(k_{g}, r_{g}\right)$ do not depend on either the number of groups, or on group composition, as long as the condition $\frac{n_{g} f}{2} \geq b\left(k_{g}\right)-\pi\left(k_{g}, r_{g}\right)$ is satisfied. Further, comparing the outcome with Proposition 2, we find that $k_{g}=k^{L}\left(r_{g}\right)$, i.e. the MFI selects the maximal $r_{g}$-feasible project size.

Let $W_{g}=W\left(k_{g}, r_{g} ; c, \beta\right)$ denote the per borrower payoff of the MFI under the optimal group lending contract with limited collusion.

Remark 10. How will our results change if $\frac{n_{g} f}{2}<b\left(k_{g}\right)-\pi\left(k_{g}, r_{g}\right)$, so that Proposition 2 does not apply? Recall from Remark 6 that in such a situation, the no default condition (ND) will be given by $\pi(k, r) \geq b(k)-\frac{n f}{2}$. Further, the $N D$ constraint must be binding at the optimum, so that we have $\pi(k, r)=b(k)-\frac{n f}{2}$. Using this information, the per borrower payoff to MFI in the group lending case can be written as

$$
F(k)-k(1+c)-(1-\beta)\left[b(k)-\frac{n f}{2}\right] .
$$

Since $\frac{n f}{2}$ is independent of $k$, it then follows immediately that the optimal $k$ is identical to $k_{I}$, the optimal project size under individual lending. Therefore the use of a group lending arrangement does not confer any efficiency gain. Of course, the lender's payoff under group lending is still higher since the presence of positive social sanctioning will allow the lender to charge a higher interest rate. In what follows, however, we abstract from this possibility and assume that under the group lending regime, the per borrower payoff to $M F I$ is $W_{g}$.

\subsection{Comparing project size and per borrower payoff under the two regimes}

We first observe that $k_{g}>k_{I} \cdot{ }^{30}$ If not, then from equation (19), we have

$$
\begin{aligned}
0 & =F^{\prime}\left(k_{g}\right)-(1+c)-(1-\beta) \frac{b^{\prime}\left(k_{g}\right)}{2} \\
& >F^{\prime}\left(k_{g}\right)-(1+c)-(1-\beta) b^{\prime}\left(k_{g}\right) \\
& \geq F^{\prime}\left(k_{I}\right)-(1+c)-(1-\beta) b^{\prime}\left(k_{I}\right)
\end{aligned}
$$

where the first inequality follows as $b^{\prime}(k)>0$, and the second inequality follows as we have assumed that $k_{I} \geq k_{g}$ and $F^{\prime \prime}(k)-(1-\beta) b^{\prime \prime}(k)<0$ (from A.2). This, however contradicts equation (18).

Second, note that the per borrower payoff of the MFI is higher under group-lending, i.e. $W_{g}>W_{I}$. Note that $W_{g} \geq W_{I}$ since $\left(k_{I}, r_{I}\right)$ satisfies the no default condition under grouplending, so that $\left(k_{I}, r_{I}\right)$ is feasible under the group lending regime as well. The strict inequality follows since the optimal choice has $k_{g}>k_{I}$.

How does the payoffs of the borrower compare under these two arrangements? Since optimally $\phi\left(k_{I}, r_{I}\right)=0$, it follows that under the individual lending regime, the payoff to the borrower $\pi\left(k_{I}, r_{I}\right)$ equals $b\left(k_{I}\right)$. On the other hand, since $\phi\left(k_{g}, r_{g}\right)=1$ under the optimal group

\footnotetext{
${ }^{30}$ Without further restrictions on $F(k)$ and $b(k)$, we have been unable to compare the optimal choices of $r_{g}$ and $r_{I}$.
} 
lending contract, the payoff to the borrower $\pi\left(k_{g}, r_{g}\right)$ equals $\frac{b\left(k_{g}\right)}{2}$. Thus, even though $k_{g}>k_{I}$, the borrower's payoff in the group lending contract need not be higher than that under the individual contract (see the example below). Intuitively, a relaxation of the no default constraint under group lending improves the lender's options. This not only allows it to increase project size, but also possibly ask for higher interests. Depending on which effect dominates, the borrower's payoff may either increase, or decrease.

The following numerical example explicitly solves for the optimal $(k, r)$ under both scenarios. It also shows that depending on the parameter values, a group lending arrangement could provide the borrower with a a lower payoff.

EXAMPLE 1. Let $F(k)=2 k^{1 / 2}, b(k)=\gamma F(k)$ where $0<\gamma<1, \beta=0, c=0$. It can be easily checked that under individual lending the optimal choice involves $k_{I}=(1-\gamma)^{2}$ and $r_{I}=1$. The net payoff from a given borrower then is $r_{I} k_{I}=(1-\gamma)^{2}$. Now observe that at the optimal individual contract, the payoff to the borrower is $b\left(k_{I}\right)$ which equals $2 \gamma(1-\gamma)$. Under group lending, the optimal choice involves $k_{g}=\frac{(2-\gamma)^{2}}{4}>(1-\gamma)^{2}$ and $r_{g}=1$. Further, the net payoff to a given borrower equals $r_{g} k_{g}=(2-\gamma)^{2} / 4$. The payoff to the borrower under group lending equals $b\left(k_{g}\right) / 2$ which equals $\frac{\gamma(2-\gamma)}{2}$.

Clearly, $\pi\left(k_{I}, r_{I}\right)=b\left(k_{I}\right)=2 \gamma(1-\gamma)>\frac{\gamma(2-\gamma)}{2}=\frac{b\left(k_{g}\right)}{2}=\pi\left(k_{g}, r_{g}\right)$ if and only if $\gamma<2 / 3$. This example thus suggests that the borrowers' utility is higher under individual lending relative to group lending if and only if the moral hazard problem (parametrized by $\gamma$ ), is relatively small.

\subsection{Optimal Choice of lending regime}

In this sub-section, we develop a framework which not only endogenies the choice of $n, m$ and $N$, but moreover compares the relative profitability of these two regimes for the MFI.

To this end, we posit costs involved in lending to the borrowers. Under individual lending with $N$ borrowers, the lending cost is denoted $C(N)$. This cost is transactional and arises in the process of disbursement of loans, as well as the collection of the interest payments. Under sequential lending, there is an additional cost arising out of the fact that with loans being staggered, there would be diseconomies of scale. Further, the longer overall repayment period in this case adds to coordination costs since additional meetings have to be held, and the MFI has to deal with borrowers at different phases of project maturity. Furthermore, it is conceivable (although we do not model it here) that some unanticipated exogenous shocks may force a borrower to default involuntary. Under a group arrangement, such shocks will then lead to other projects being liquidated and/or social sanctions being invoked, thus increasing the overall cost of group lending. In general, then, one will expect group lending arrangements to have an additional cost component that depends on $n$, the number of borrowers in the group. We denote this component of the cost as $\lambda G(n), \lambda>0$, so that with $m$ groups this cost becomes $\lambda m G(n)$. Thus the total costs under group lending is $C(m n)+\lambda m G(n)$. We assume that $C(N)$ and $G(n)$ are increasing and convex in their respective arguments, with $C(0)=G(0)=0$.

We first consider the decision problem of the lender under individual lending. As argued earlier in sub-section 5.1 earlier, for every borrower the MFI lends to, the optimal contract is $\left(k_{I}, r_{I}\right)$ and the optimal per borrower payoff is $W_{I}$. With $N$ borrowers, the net payoff of the MFI is then given by

$$
N W_{I}-C(N)
$$

Let $N_{I}^{*}$ denote the optimal number of borrowers under individual lending. 
Under the group lending regime, the per borrower payoff to the lender from a group equals $W_{g}$. Therefore the total net payoff of the MFI when it lends to $m$ groups, with each group containing $n$ borrowers, is given by

$$
n m W_{g}-C(m n)-m \lambda G(n) .
$$

Let $n^{*}$ be the minimum even integer for which the no default condition holds, i.e. $\frac{n^{*} f}{2} \geq b\left(k_{g}\right)-$ $\pi\left(k_{g}, r_{g}\right)$. Since the lender's maximand can equivalently be written as $m n\left[W_{g}-\frac{C(m n)}{m n}-\frac{\lambda G(n)}{n}\right]$, it follows that at the optimal choice of $m$ and $n, n$ must equal $n^{*}$. The optimization problem for the lender thus reduces to choosing an $m$ so as to maximize

$$
m n^{*} W_{g}-C\left(m n^{*}\right)-m \lambda G\left(n^{*}\right) .
$$

Let $\left(m^{*}, n^{*}\right)$ denote the optimal choice under the group lending scheme.

We now provide a simple condition that determines whether the lender prefers group or individual lending. Let $\lambda^{*}$ satisfy

$$
W_{g}-W_{I}=\frac{\lambda^{*} G\left(n^{*}\right)}{n^{*}} .
$$

Given that $W_{g}>W_{I}, \lambda^{*}$ as defined in (20) is unique and strictly positive. We now argue that the MFI prefers individual lending to group lending if and only if $\lambda>\lambda^{*}$.

First consider the case where $\lambda>\lambda^{*}$. If the lender uses the individual lending program and lends to $m^{*} n^{*}$ borrowers, its net profit would have been $m^{*} n^{*} W_{I}-C\left(m^{*} n^{*}\right)$. Note that this payoff exceeds that from group lending if and only if $m^{*} n^{*} W_{I}-C\left(m^{*} n^{*}\right)>m^{*} n^{*} W_{g}-$ $C\left(m^{*} n^{*}\right)-m^{*} \lambda G\left(n^{*}\right)$, i.e. $W_{g}-W_{I}<\frac{\lambda G\left(n^{*}\right)}{n^{*}}$, which is true given that $\lambda>\lambda^{*}$.

Next consider the case where $\lambda<\lambda^{*}$. Let $m$ be defined as $\frac{N_{I}^{*}}{n^{*}}$, and consider a group lending regime where the lender lends to $m$ groups, each containing $n^{*}$ lenders. Since $\lambda<\lambda^{*}$, a similar argument as above establishes that group lending will be the preferred choice for the MFI. ${ }^{31}$

Finally, note that under the group lending the marginal net benefit per borrower is simply given by $W_{g}-\frac{\lambda G\left(n^{*}\right)}{n^{*}}$ while the marginal net benefit per borrower is $W_{I}$. Thus, ignoring integer constraint on the choice of the borrowers, it follows that the total number of borrowers under the group lending scheme $m n^{*}$ is strictly greater than $N_{I}^{*}$ if and only if $\lambda<\lambda^{*}$. We summarize the above discussions in the following proposition.

Proposition 5. Consider the MFI's choice over both the lending regimes, individual versus group lending with limited collusion.

(i) The optimal project size is larger under group-lending, i.e. $k_{g}>k_{I}$.

(ii) A borrower's payoff under group lending is strictly greater than that under individual lending if and only if $b\left(k_{I}\right)<\frac{b\left(k_{g}\right)}{2}$.

(iii) The MFI prefers the individual lending regime to the group lending regime if and only if $\lambda>\lambda^{*}$, where $\lambda^{*}$ solves equation (20).

(iv) Outreach is higher under a group-lending mechanism if and only if the MFI prefers grouplending to individual lending.

\footnotetext{
${ }^{31}$ This argument uses the fact $\frac{N}{n^{*}}$ is an integer. If this was not the case, one could choose $\hat{m}$ to be the largest integer for which $\hat{m} n^{*} \leq N$ and then use a mixed scheme, where $\hat{m} n^{*}$ borrowers are served under the group regime while the remaining borrowers $N-\hat{m} n^{*}$ are served individually. The total payoff from this scheme must be strictly higher than the individual regime whenever $\lambda<\lambda^{*}$.
} 
We should point out that this paper is one of the very few in the literature to compare the outcomes, in particular project size and outreach, under individual and group lending. One of the papers that does perform this exercise is de Quidt et. al. (2012) who compares the behavior of for-profit MFIs with market power, with not-for-profit lenders. They consider a framework with simultaneous lending and social capital. They find that the MFI prefers group contracts when the social capital is large. In contrast to our results however, they find that borrowers always prefer a group lending contract to an individual lending contract.

In the next section, we perform some comparative statics analysis, arguing that many of these hinge on how they affect $\lambda^{*}$. Given Proposition 5(iii), note that one can interpret an increase in $\lambda^{*}$ as indicating whether group lending becomes relatively more profitable compared to individual lending. In the ensuing comparative statics analysis, we assume that $n^{*}$ satisfies $\frac{n^{*} f}{2}>b\left(k_{g}\right)-\pi\left(k_{g}, r_{g}\right)$. This assumption, which holds generically, ensures that small changes in the parameters (like $c, \beta$ etc.) do not change the optimal group size.

\section{Comparative Statics: Some Policy Relevant Issues}

\subsection{Change in the opportunity cost of fund for the MFI}

One motivation for this exercise comes from the fact that in India, policy makers have recommended the provision of subsidized funds to MFIs (Malegam Committee Report, 2011). Clearly such increased access to funding can be formalized as a decrease in $c$.

To examine the impact of a small decline in $c$, totally differentiate equations (18) and (19) with respect to $c$, to get

$$
\begin{aligned}
\frac{d k_{I}}{d c} & =\frac{1}{F^{\prime \prime}\left(k_{I}\right)-(1-\beta) b^{\prime \prime}\left(k_{I}\right)}, \\
\frac{d k_{g}}{d c} & =\frac{1}{F^{\prime \prime}\left(k_{g}\right)-(1-\beta) b^{\prime \prime}\left(k_{g}\right) / 2} .
\end{aligned}
$$

From A.2, it is immediate that $\frac{d k_{I}}{d c}<0$ and $\frac{d k_{g}}{d c}<0$. Thus with a decrease in $c$, the optimal project size increases under both individual, as well as group lending regimes. Further, recalling that the payoffs of all borrowers equal $b\left(k_{I}\right)$ under individual lending, and $b\left(k_{g}\right) / 2$ under grouplending, the payoff to a borrower must also increase since project size increases under both lending schemes.

To examine the effect on the per borrower payoff $W_{I}$ of the MFI, one can use the envelope theorem to show that $\frac{d W_{I}}{d c}=-k_{I}$, and $\frac{d W_{g}}{d c}=-k_{g}$, so that both $W_{I}$ and $W_{g}$ increases with a decline in $c$. Further, since $k_{g}>k_{I}, W_{g}$ increases relatively more compared to $W_{I}$, so that $W_{g}-W_{I}$ increases. Thus from equation (20), it follows that $\lambda^{*}$ will increase for a small decrease in $c$, and thus group lending becomes relatively more profitable. ${ }^{32}$

\footnotetext{
${ }^{32}$ This argument assumes that the constraint on $n^{*}$, namely $\frac{n^{*} f}{2} \geq b\left(k_{g}\right)-\pi\left(k_{g}, r_{g}\right)$ is not binding. If this constraint binds, one also needs to consider the effect of change in $n^{*}$. This is because with a fall in $c, k_{g}$ will increase, and this will increase $n^{*}$. As long as, $G(n) / n$ does not increase too quickly with $n$, this result, however, is expected to hold.
} 


\subsection{For-profit MFIs: Change in $\beta$}

Given that the recent crisis in the MFI sector in Andhra Pradesh, India, was preceded by some large MFIs entering the capital market (see de Quidt et al, 2012), the analysis of for-profit MFIs and the possibility of mission drift have gained in importance. Using the framework developed in the preceding section, such mission drift can be interpreted as a lowering of $\beta$.

How does a small change in $\beta$ affect the outcome? Totally differentiating equations (18) and (19) with respect to $\beta$, we find that

$$
\begin{aligned}
\frac{d k_{I}}{d \beta} & =-\frac{b^{\prime}\left(k_{I}\right)}{F^{\prime \prime}\left(k_{I}\right)-(1-\beta) b^{\prime \prime}\left(k_{I}\right)} \\
\frac{d k_{g}}{d \beta} & =-\frac{b^{\prime}\left(k_{g}\right) / 2}{F^{\prime \prime}\left(k_{g}\right)-(1-\beta) b^{\prime \prime}\left(k_{g}\right) / 2} .
\end{aligned}
$$

Given A.2, the optimal project size decreases under both individual, as well as group lending regimes with a fall in $\beta$. Further, recalling that the payoffs of all borrowers equal $b\left(k_{I}\right)$ under individual lending, and $b\left(k_{g}\right) / 2$ under group-lending, the payoff to a borrower must also decrease since project size decreases under both lending schemes.

We next examine how a change in $\beta$ affects the per borrower payoff $W(k, r ; c, \beta)$ of the MFI under the two regimes. To this end, one can use the envelope theorem to show that under individual lending $\frac{d W_{I}}{d \beta}=\frac{\partial W_{I}}{\partial \beta}=b\left(k_{I}\right)$, whereas $\frac{d W_{g}}{d \beta}=\frac{\partial W_{g}}{\partial \beta}=\frac{b\left(k_{g}\right)}{2}$ under group-lending. With a decrease in $\beta$, both $W_{I}$ and $W_{g}$ will decline. However, $W_{g}$ will decline relatively more compared to $W_{I}$, if and only if $b\left(k_{I}\right)<\frac{b\left(k_{g}\right)}{2}$. ${ }^{33}$ Thus, under the same conditions, $\lambda^{*}$ will decrease following a small decrease in $\beta$, and group-lending becomes relatively less attractive to the MFI.

\subsection{Ceiling on the interest rate $r$}

Our analysis so far has assumed that the lender is free to choose $r$, the interest rate on the loan. In many realistic scenarios, however, the MFI will be constrained to charge an interest rate no higher than some exogenously specified rate $r_{0}$, where $r_{0}>c$. In India, for example, the Malegam Committee Report (2011) setup by the RBI stipulated a ceiling of $26 \%$ on MFI interest rates. How does the lowering of such a ceiling affect the relative profitability of group versus individual lending?

In order to obtain sharp predictions we assume that $\beta=0$ and focus on the case where the ceiling $r_{0}$ is binding under both the lending arrangements, so that $r_{g}=r_{I}=r_{0}$. Denote by $k_{i}\left(r_{0}\right), i=g, I$, the optimal project sizes under group and individual lending. As before the no default constraints bind in both cases so that $\phi\left(k_{I}\left(r_{0}\right), r_{0}\right)=0$ and $\phi\left(k_{g}\left(r_{0}\right), r_{0}\right)=1$. Thus,

$$
\frac{\partial W_{g}}{\partial r_{0}}-\frac{\partial W_{I}}{\partial r_{0}}=k_{g}\left(r_{0}\right)-k_{I}\left(r_{0}\right)+\left(r_{0}-c\right)\left[\frac{\partial k_{g}\left(r_{0}\right)}{\partial r_{0}}-\frac{\partial k_{I}\left(r_{0}\right)}{\partial r_{0}}\right]
$$

Since $k_{g}\left(r_{0}\right)>k_{I}\left(r_{0}\right)$, this difference is strictly positive for $r_{0}$ sufficiently close to $c$, More generally, it is possible to show that $\frac{\partial W_{g}}{\partial r_{0}}-\frac{\partial W_{I}}{\partial r_{0}}>0$ if and only if ${ }^{34}$

$$
F^{\prime}\left(k_{I}\right)-b^{\prime}\left(k_{I}\right)>F^{\prime}\left(k_{g}\right)-b^{\prime}\left(k_{g}\right) / 2 .
$$

\footnotetext{
${ }^{33}$ See example 1 for this possibility.

${ }^{34}$ Totally differentiating the no default constraints, it is possible to check that $\frac{\partial k_{g}\left(r_{0}\right)}{\partial r_{0}}=$ $-\frac{k_{g}\left(r_{0}\right)}{\left(b^{\prime}\left(k_{g}\right) / 2-F^{\prime}\left(k_{g}\right)+\left(1+r_{0}\right)\right)}$ and $\frac{\partial k_{I}\left(r_{0}\right)}{\partial r_{0}}=-\frac{k_{I}\left(r_{0}\right)}{\left(b^{\prime}\left(k_{I}\right)-F^{\prime}\left(k_{I}\right)+\left(1+r_{0}\right)\right)}$. The result now follows from this.
} 
If the preceding condition holds, then $\lambda^{*}$ will decrease with a small decrease in $r_{0}$, and thus individual lending becomes relatively more profitable.

\subsection{Reservation utility}

So far we have assumed away the individual rationality constraint of the borrower. In a changing economic environment, however, it will be of interest to explicitly allow for this constraint so that one can study how a change in the reservation utility of a borrower affects the equilibrium arrangements. If we denote by $\bar{u}$ the reservation utility of the borrower, the optimization problem under both the lending regimes must now explicitly incorporate the individual rationality constraint, namely that $\pi(k, r)-\bar{u} \geq 0$, along with the corresponding incentive constraints.

As is expected, the optimal solution of course depends on the actual magnitude of $\bar{u}$. In particular, under individual lending, one can show that there exists $\left(u_{I}, u^{I}\right)$, where $u_{I}=b\left(k_{I}\right)<$ $u^{I}=b\left(k^{*}(c)\right)$ such that (i) for $\bar{u}<u_{I}$, the individual rationality constraint does not bind, and the equilibrium payoff to the borrower equals $u_{I}>\bar{u}$, (ii) for $u_{I}<\bar{u}<u^{I}$, the individual rationality, as well as the incentive constraint bind, i.e. at the solution $\left(k_{I}, r_{I}\right)$, we have $b\left(k_{I}\right)=\bar{u}$ and $\phi\left(k_{I}, r_{I}\right)=0$, and (iii) for $\bar{u}>u^{I}$, only the individual rationality constraint binds and the solution is efficient in that the project size equals $k^{*}(c)$.

Similarly, the solution under the group lending case, one can shown the existence of $\left(u_{g}, u^{g}\right)$ with $u_{g}=\frac{b\left(k_{g}\right)}{2}<u^{g}=\frac{b\left(k^{*}(c)\right.}{2}$ such that (i) for $\bar{u}<u_{g}$, only the incentive constraint $\phi(k, r)=1$ binds, and the equilibrium payoff to borrower equals $u_{g}=\frac{b\left(k_{g}^{*}\right)}{2}$, (ii) for $u_{g}<\bar{u}<u^{g}$, both the constraints bind and the solution $\left(k_{g}, r_{g}\right)$ is obtained from $\frac{b\left(k_{g}\right)}{2}=\bar{u}$ and $\phi\left(k_{g}, r_{g}\right)=1$, and finally (iii) for $\bar{u}>u^{g}$, only the individual rationality constraint binds, and the project size is efficient, i.e. $k^{*}(c)$. Further, since $\frac{b\left(k^{*}(c)\right)}{2}<b\left(k^{*}(c)\right)$, it follows that $u^{g}<u^{I} .^{35}$

How does a small increase in $\bar{u}$ affect $\lambda^{*}$ ? Focussing on the case where the individual rationality constraints bind for both of these cases, we have $\bar{u} \in\left(u^{g}, u^{I}\right) .{ }^{36}$ For $\bar{u}$ in this range, both $W_{g}$ and $W_{I}$ decreases with an increase in $\bar{u}$, however, $W_{g}$ decreases at a faster rate than $W_{I}$. This is because for $\bar{u}$ in this range, in the group lending contract, the project choice is $k^{*}(c)$ and thus $\left|\frac{\partial W_{g}}{\partial \bar{u}}\right|=1$, while $\left|\frac{\partial W_{I}}{\partial \bar{u}}\right|<1$. Therefore, a small increase in $\bar{u}$ will lead to a decrease in $\lambda^{*}$ so that individual lending becomes relatively more profitable. ${ }^{37}$

\subsection{Effects of increased competition: Transition to individual lending?}

In recent years there has been a large increase in competition in the MFI sector all over the world, including in India. While such competition has been linked to various issues in the literature, e.g. double-dipping, default and even farmer suicides, ${ }^{38}$ a detailed analysis of all such aspects is beyond the scope of the present paper.

\footnotetext{
${ }^{35}$ The detailed derivation of these results are available on request.

${ }^{36} \mathrm{It}$ is easy to note that for $\bar{u}>u^{I}, k_{g}=k_{I}$ with $W_{g}=W_{I}$ and thus, for any $\lambda>0$, individual lending must be preferred by the lender.

${ }^{37}$ However, when $\bar{u}$ is low, the effect of such an increase in $\bar{u}$ is ambiguous and depends on $u_{I}$ and $u_{g}$. For instance when $b\left(k_{I}\right)=u_{I}>u_{g}=\frac{b\left(k_{g}\right)}{2}$ and $\bar{u} \in\left(u_{g}, u_{I}\right)$, an increase in $\bar{u}$ leads to a decrease in the payoff from group lending, while the lender's payoff from the individual lending contract remains unchanged shifting $\lambda *$ to the left. In such situations, an increase in $\bar{u}$ will make individual lending becomes relatively more profitable. The opposite result, of course holds when $u_{g}>u_{I}$.

${ }^{38}$ We refer the readers to Guha and Roy Chowdhury, 2013, and de Quidt et al (2012), among others, for a discussion of some of these issues.
} 
Here we focus on a phenomenon that was roughly contemporaneous with the increase in MFI competition, namely a move away from group to individual lending in many cases. While such a transition can of course be triggered by various reasons, e.g. by an exogenous coordinated shock in the form of a cyclone as in case of Grameen I, we shall argue that our framework can provide a rich explanation for this transition that links it to the increased competition among MFIs.

To this end we focus on two possible effects of such increased competition, namely (i) increased competition for donor funds, possibly resulting in a higher opportunity cost of fund $c$ for the MFIs, and (ii) an increase in the reservation utility of the borrowers, i.e. $\bar{u}$, as the borrowers have access to competing MFIs. From the preceding analysis recall that with an increase in $c$, as well as $\bar{u}$, there is a decrease in $\lambda^{*}$, so that individual lending becomes relatively more attractive for the MFI. Similarly, a fall in the interest rate itself will have effects similar to that of a decline in the interest rate ceiling, in which case individual lending will tend to become relatively more profitable (see sub-section 6.3).

Another possible link would arise in case increased competition was also accompanied, as has been suggested by some commentators, by mission drift, leading to a fall in $\beta$. Our analysis in sub-section 6.2 would then suggest that such a decrease in $\beta$ may make individual lending more attractive for the MFI, with example 1 suggesting that this is more likely if the moral hazard problem is relatively severe. Further, consider a scenario where the interest rate is exogenously determined in the short run, though responsive to competitive pressures in the long run. In that case an increase in the number of MFIs can be expected to lower the exogenously given interest rates in the long run. Consequently, the analysis in section 6.3 suggests that this would cause a shift towards individual lending.

We finally examine the effects of a change in social capital/sanctions on this trade-off between group and individual lending (we are indebted to a referee for drawing our attention to this possibility). This exercise is of some importance since, with the sustained process of urbanization going on in most LDCs, it may be conjectured that social capital would decline among rural borrowers. To begin with note that a change in $f$ does not affect $\left(k_{g}, n_{g}\right)$. However, from Proposition 2 we know that the group size $n^{*}$ must satisfy $\frac{n^{*} f}{2} \geq b\left(k_{g}\right)-\pi\left(k_{g}, r_{g}\right)$. Thus, a sustained fall in $f$ will lead to an increase in $n^{*}$. Given that $G(n)$ is convex and $G(0)=0$, it then follows from equation (20) that $\lambda^{*}$ will decrease. Consequently, with a decline in social capital, individual lending will become relatively more attractive for the MFIs.

\section{Conclusion}

Given the recent success of various micro-finance programs, in particular the high rates of repayment, ${ }^{39}$ there is a natural interest in examining whether the innovative institutional features, in particular dynamic features like sequential financing and dynamic joint liability used by many MFIs, play a role in their success.

We argue that a unified explanation of both these aspects can be built around dynamic incentives, in particular the simple idea that sequential lending can help resolve problems arising out of coordinated default. Further it helps clarify how social capital interacts with sequential financing in incentivizing repayment. In fact, this is one of the few papers in the literature

\footnotetext{
${ }^{39}$ Hossein (1988), Morduch (1999) and Christen, Rhyne and Vogel (1994), all argue that the Grameen Bank has a repayment rate in excess of 90 percent.
} 
that can help explain the fact that empirical findings regarding the impact of social capital is decidedly mixed.

In addition, the present framework also provides an explanation for early and frequent repayment schemes. Inter alia, it identifies a synergy between IFR and sequential lending, arguing that a lending mechanism involving both is more than the sum of its parts. Moreover, this synergistic effect has important implications for empirical analysis as well, suggesting that while testing for the efficacy of group lending, any analysis that considers either sequential lending or IFR in isolation, may seriously under-estimate the power of the two taken together. ${ }^{40}$

Further, the tractability of the basic model allows us to endogenize the choice of several variables of interest, including the choice of loan scheme, one of the few papers in the literature to do so. Finally, we put our theory to the test, examining if it can provide an explanation of a somewhat puzzling fact, namely the switch from group to individual lending in recent years. We trace this transition to the increase in MFI competition that happened at the same time. Further, we show that the intuition for this result hinges on the basic theoretical point of our paper, namely that the no default constraint is relaxed under group lending.

\section{Appendix A: Lemma 2}

Lemma 2 Consider $k_{1}, k_{2}$ such that $0<k_{2}<k_{1}<k^{0}(r)$. Under A.1(ii), $\phi\left(k_{2}, r\right)<\phi\left(k_{1}, r\right)$.

Proof. Fix $r$ and pick $k_{1}, k_{2}$ such that $k_{2}<k_{1}<k^{0}(r)$. Since $k_{i}<k^{0}(r)$, we have $\pi\left(k_{i}, r\right)>0$ for $i=1,2$. We will show that $\phi\left(k_{2}, r\right)<\phi\left(k_{1}, r\right)$. Since $F(k)$ is strictly concave and $F(0)=0$, we have that $\frac{F\left(k_{2}\right)}{k_{2}}>\frac{F\left(k_{1}\right)}{k_{1}}$. Using this and the fact that $\pi\left(k_{i}, r\right)>0$ for $i=1,2$, it follows that

$$
\frac{F\left(k_{2}\right)}{F\left(k_{1}\right)}<\frac{F\left(k_{2}\right)-k_{2}(1+r)}{F\left(k_{1}\right)-k_{1}(1+r)} .
$$

Since by A.1(ii), $\frac{b\left(k_{2}\right)}{b\left(k_{1}\right)} \leq \frac{F\left(k_{2}\right)}{F\left(k_{1}\right)}$, we thus have

$$
\frac{b\left(k_{2}\right)}{b\left(k_{1}\right)}<\frac{F\left(k_{2}\right)-k_{2}(1+r)}{F\left(k_{1}\right)-k_{1}(1+r)} .
$$

Using the definition of $\phi(k, r)$, it then follows that

$$
\phi\left(k_{2}, r\right)=\frac{b\left(k_{2}\right)}{F\left(k_{2}\right)-k_{2}(1+r)}-1<\frac{b\left(k_{1}\right)}{F\left(k_{1}\right)-k_{1}(1+r)}-1=\phi\left(k_{1}, r\right) .
$$

\section{Appendix B: Lemma 3}

Lemma 3 Fix $k>0$ such that $\pi(k, r)>0$. Suppose that project size $k$ is $r$-feasible under limited collusion with a two stage group lending arrangement. Then, $k$ is $r$-feasible in a two stage group lending arrangement in which the lender uses only IFR contracts.

\footnotetext{
${ }^{40}$ In an earlier version of this paper we also briefly examine the effects of gestation lags and uncertainty in project returns, arguing that the results in this paper are largely robust to these extensions. Preliminary investigations suggest that allowing for uncertain returns with asymmetric information may yield a framework that integrates the intuition developed in Jain and Mansuri (2003) into our framework, thus providing a unified explanation of not only sequential lending and dynamic joint liability, but also the persistence of informal lenders. In fact, similar results may obtain if the project involves gestation lags. We plan to take up these issues in future work.
} 
Proof. Consider any repayment scheme $y^{i}\left(t^{i}+\tau, k\right)$ that satisfies limited liability and is $r$-feasible.

Given $y^{i}$, denote by $P_{y^{i}}^{i}\left(t^{i}+\tau\right)$ (resp. $D_{y^{i}}^{i}\left(t^{i}+\tau\right)$ ) the continuation (resp. default payoffs, gross of the of social sanctions) at $t^{i}+\tau$, of a borrower in group $i$. Further, let $l_{y^{i}}\left(t^{i}+\tau\right)$ denote the number of borrowers who are affected adversely because of a default at $t^{i}+\tau$. We will abuse notations slightly and denote the repayment scheme according to the IFR scheme simply by $I$.

Step 1. For any $y^{i}, P_{I}^{i}\left(t^{i}+\tau\right) \geq P_{y^{i}}^{i}\left(t^{i}+\tau\right)$.

To see why this is true, first, consider a borrower in group 1 who receives the loan at $t^{1}=0$. For all $t \leq 1$, the result is clearly true and follows from the arguments in Lemma 1 . Now for $t \geq 1$, the continuation payoff of any borrower under an IFR scheme is zero. The fact that the repayment scheme $y^{i}\left(t^{i}+\tau, k\right) \geq 0$, then establishes that the continuation payoff of the borrower under any other repayment obligation can not be more than that under an IFR scheme. A similar argument holds for the second group of borrowers who receive their loan at $t^{2}$.

Step 2. $D_{y^{i}}^{i}\left(t^{i}+\tau\right)=D_{I}^{i}\left(t^{i}+\tau\right)$.

This follows as $D_{y^{i}}^{i}\left(t^{i}+\tau\right)$ and $D_{I}^{i}\left(t^{i}+\tau\right)$ both equal $b(k)(1+\tau)$.

Note that Steps 1 and 2 together yield

Step 3. $l_{y^{i}}\left(t^{i}+\tau\right) \leq l_{I}\left(t^{i}+\tau\right)$.

From Steps 2 and 3 we have

Step 4. $\quad D_{y^{i}}^{i}\left(t^{i}+\tau\right)-l_{y^{i}}\left(t^{i}+\tau\right) f \geq D_{I}^{i}\left(t^{i}+\tau\right)-l_{I}\left(t^{i}+\tau\right) f$.

Finally, if $P_{y^{i}}^{i}\left(t^{i}+\tau\right) \geq D_{y^{i}}^{i}\left(t^{i}+\tau\right)-l_{y^{i}}\left(t^{i}+\tau\right) f$, then

$$
\begin{aligned}
P_{I}^{i}\left(t^{i}+\tau\right) & \geq P_{y^{i}}^{i}\left(t^{i}+\tau\right) \quad(\text { from Step } 1) \\
& \geq D_{y^{i}}^{i}\left(t^{i}+\tau\right)-l_{y^{i}}\left(t^{i}+\tau\right) f \\
& \geq D_{I}^{i}\left(t^{i}+\tau\right)-l_{I}\left(t^{i}+\tau\right) f(\text { from Step 4). }
\end{aligned}
$$

Thus, if at $t^{i}+\tau$, the no default condition is satisfied for some borrower given the repayment scheme $y^{i}\left(t^{i}+\tau, k\right)$, it will also be satisfied under the IFR scheme. This proves Lemma 3 .

Furthermore, it is straightforward to verify that under IFR, the net default incentive for an individual borrower in group $i$ is decreasing over time.

\section{Appendix C: Lemma 4}

Lemma 4 Under A.1, we have

(a) $k \leq k_{1}(r)$ if and only if $\phi(k, r) \leq \frac{\phi(k, r)}{b(k)}$, and

(b) $k \leq k_{2}(r)$ if and only if $\phi(k, r) \leq \frac{k(1+r)}{F(k)}$.

Proof. (a) Recall that at $k_{1}(r), \phi\left(k_{1}(r), r\right)=\frac{\pi(k, r)}{b(k)}$.

Since $\frac{\pi(k, r)}{b(k)}=\frac{1}{1+\phi(k, r)}$, and $\phi(k, r)$ is an increasing function of $k$ (Lemma 2), it then immediately follows that $k \leq k_{1}(r)$ if and only if $\phi(k, r) \leq \frac{\pi(k, r)}{b(k)}$. 
(b) Recall that at $k_{2}(r), \phi\left(k_{2}(r), r\right)=\frac{k_{2}(r)(1+r)}{F\left(k_{2}(r)\right.}$. Observe that

$$
\phi(k, r)=\frac{b(k)}{F(k)-k(1+r)}-1 \leq \frac{k(1+r)}{F(k)},
$$

if and only if

$$
b(k) F(k) \leq(F(k))^{2}-(k(1+r))^{2} .
$$

Dividing both sides by $(F(k))^{2}$, condition $(* *)$ holds if and only if

$$
\frac{b(k)}{F(k)}+\left(\frac{k(1+r)}{F(k)}\right)^{2} \leq 1 .
$$

Since (a) $F(k)$ is a concave function of $k, \frac{k(1+r)}{F(k)}$ is an increasing function of $k$ and (b) by A.1(ii) $\frac{b(k)}{F(k)}$ is non-decreasing in $k$, it thus follows that if $(* *)$ holds for some $k>0$, then for $k^{\prime}<k$, condition $(* *)$ will hold as well.

\section{Appendix D: Proposition 3}

\section{Proposition 3.}

(a) [Necessity.] If a project size $k$ is $r$-feasible, then $k \leq k^{C}(r)$.

(b) [Sufficiency.] Suppose that $k<k^{C}(r)$, then there exists $n$ and a group lending arrangement $<n, m, t^{2}>$ with IFR for which $k$ is $r$-feasible.

Proof of Proposition 3.

(a) [Necessity.] Let $<n, m, k, t^{2}>$ be the group arrangement with IFR repayment schemes for which $k$ is $r$-feasible. By Lemma 4 , it is sufficient to show that $k \leq k^{C}(r)$.

From equation (16) and (17) in the text, we have

$$
\phi(k, r) \leq t^{2} \leq \frac{\pi(k, r)}{b(k)} .
$$

From Lemma 4, it then follows that $k \leq k_{1}(r)$.

We now show that $k \leq k_{2}(r)$. Consider the default payoff of the group at $t^{2}$. This is given by

$$
D^{G}\left(t^{2}\right)=(n-m) b(k)\left(1-t^{2}\right)+m b(k) .
$$

Observe that the group's continuation no default payoff at $t^{2}$ depends on whether $t^{2}$ is greater than, or less than $\frac{k(1+r)}{F(k)}$. In particular, if $t^{2}<\frac{k(1+r)}{F(k)}$, then the continuation payoff is $n \pi(k, r)$ while for $t^{2}>\frac{k(1+r)}{F(k)}$, the continuation payoff is $(n-m) F(k)\left(1-t^{2}\right)+m \pi(k, r)$. Hence the net default payoff for the group, for $t^{2}<\frac{k(1+r)}{F(k)}$ equals

$$
A\left(t^{2}\right)=(n-m) b(k)\left(1-t^{2}\right)+m b(k)-n \pi(k, r) .
$$

On the other hand, if $t^{2}>\frac{k(1+r)}{F(k)}$, the net payoff of the group from default equals

$$
B\left(t^{2}\right)=(n-m) b(k)\left(1-t^{2}\right)+m b(k)-\left[(n-m) F(k)\left(1-t^{2}\right)+m \pi(k, r) .\right.
$$


It is easy to check that $A\left(t^{2}\right)$ is decreasing in $t^{2}$ and since $\forall k>0, F(k)>b(k), B\left(t^{2}\right)$ is increasing in $t^{2}$. Furthermore, $A\left(t^{2}\right)=B\left(t^{2}\right)$ at $t^{2}=\frac{k(1+r)}{F(k)}$. Therefore, it follows that if $A\left(t^{2}\right)>0$ at $t^{2}=\frac{k(1+r)}{F(k)}$, then for all $t^{2} \in[0,1]$, default must be profitable when the second group gets the loan at $t^{2}$. Thus the loan size $k$ cannot be $r$-feasible. Consequently, if $k$ is feasible, then at $t=\frac{k(1+r)}{F(k)}$,

$$
A\left(\frac{k(1+r)}{F(k)}\right)=(n-m) b(k)\left(1-\frac{k(1+r)}{F(k)}\right)+m b(k)-n \pi(k, r) \leq 0 .
$$

Rearranging terms in $(21)$ we have $(n-m) b(k)+m b(k)-n \pi(k, r) \leq(n-m) b(k) \frac{k(1+r)}{F(k)}$. Further simplification leads to

$$
n[b(k)-\pi(k, r)] \leq(n-m) b(k) \frac{k(1+r)}{F(k)} \leq n \pi(k, r) \frac{k(1+r)}{F(k)},
$$

where the final inequality follows from (14) in text (the default constraint at $t=0$ ). Next dividing through by $n \pi(k, r)$, we have

$$
\frac{b(k)}{\pi(k, r)}-1=\phi(k, r) \leq \frac{k(1+r)}{F(k)} .
$$

Thus, by Lemma $4, k \leq k_{2}(r)$.

(b) [Sufficiency.] Suppose $k<k^{C}(r)$. If $k \leq k^{I}(r)$, then a group consisting of $n$ borrowers, $n \geq 1$, in which all borrowers are given the loan $k$ at $t=0$ is feasible. Therefore, assume that $k>k^{I}(r)$. We now construct a feasible group lending arrangement such that $k$ is $r$-feasible.

Since $k<k^{C}(r)$, by Lemma $4, \phi(k, r)<\min \left\{\frac{\pi(k, r)}{b(k)}, \frac{k(1+r)}{F(k)}\right\}$.

For any $\epsilon>0$, let $\frac{b(k)}{\pi(k, r)}+\epsilon$ be a rational number. Since rational numbers are dense in reals, it follows that one can choose an $\epsilon$ that is arbitrarily close to zero. Given such a choice of $\epsilon$, consider a pair of positive integers $(n, m)$ ( $n$ and $m$ depend on $\epsilon$ but we drop this dependence for notational simplicity) such that

$$
\frac{b(k)}{\pi(k, r)}+\epsilon=\frac{n}{n-m}
$$

Since $k>k^{I}(r)$, we have $\frac{b(k)}{\pi(k, r)}>1$ and thus $n>m$.

Consider now a group consisting of $n$ members of whom $(n-m)$ are given a loan of size $k$ at $t=0$. By construction of $(n, m)$, the no default condition at $t=0$ is given by

$$
(n-m) b(k) \leq n \pi(k, r)
$$

which is satisfied because of equation (22) and the fact that $\epsilon>0$.

Let the remaining $m$ members of the group be given the loan at $t^{2}(\epsilon)$, where $t^{2}(\epsilon)$ satisfies

$$
n[b(k)-\pi(k, r)]=(n-m) b(k) t^{2}(\epsilon) .
$$

Using the definition of $(n, m)$ and recalling that $\phi(k, r)=\frac{b(k)}{\pi(k, r)}-1$, the above equation can be rewritten as

$$
\phi(k)+\epsilon\left[1-\frac{\pi(k, r)}{b(k)}\right]=t^{2}(\epsilon) .
$$


It follows that for $\epsilon$ close to zero, $t^{2}(\epsilon)$ is arbitrarily close to $\phi(k, r)$. Since $\phi(k, r)<\frac{k(1+r)}{F(k)}$, it then follows that one can choose $\epsilon$ sufficiently small such that $t^{2}(\epsilon)<\frac{k(1+r)}{F(k)}$. Given that the repayment scheme is an IFR, it follows that at $t^{2}(\epsilon)$, the $(n-m)$ members in the first group are yet to meet their repayment obligations. Thus the continuation payoff for the entire group at $t^{2}(\epsilon)$ equals $n \pi(k, r)$ and the no default condition at $t=t^{2}(\epsilon)$ is given by

$$
(n-m) b(k)\left(1-t^{2}(\epsilon)\right)+m b(k) \leq n \pi(k, r) .
$$

This is satisfied because of construction of $t^{2}(\epsilon)$ (see equation (23)).

Finally, consider $t=1$. If the second group members have already repaid their loan by this date, then there is nothing more to prove. Otherwise, the loan is yet to be repaid and thus the continuation payoff of the group equals $m \pi(k, r)$. Since $\phi(k, r)<\frac{\pi(k, r)}{b(k)}$, for $\epsilon$ small, it follows from equation (23) that $t^{2}(\epsilon)<\frac{\pi(k, r)}{b(k)}$ for $\epsilon$ small and thus the no default condition is satisfied at $t=1$ as well.

\section{Appendix E: Some Additional Proofs}

\subsection{Discussion of assumptions in Proposition 2}

Here we discuss in greater details the role played by some of the assumptions made earlier in Proposition 2, namely that repayments are non-negative, and that cross-subsidizing is not allowed.

In case negative repayments are possible (so that the MFI may pay the borrower), we argue that any project size that yields a strictly positive payoff to a borrower is feasible. Consider the scheme in which every borrower pays the MFI an amount $F(k)$ at every instant during the entire period the project is active. When all borrowers have completed their projects, the MFI then returns the amount $F(k)-k$ to each of the borrowers. In case of default, all projects are dissolved and the MFI also confiscates all of the payments that it has received till that point. Under such a scheme, even when the first group of borrowers have completed their projects, a default by members in the second group will adversely affect the payoffs of the first group, leading to social sanctions. Therefore such a scheme can always deter willful default by the second group of borrowers, enabling the lender to support any project size.

Such a scheme however is problematic on at least three counts. First, the implementation of this scheme will require the MFI to credibly commit to returning the amount due to the borrowers. Second, such a mechanism will be vulnerable to collusion between the MFI and individual borrower(s). This is because if a borrower defaults, then under this scheme the MFI will be able to save $(n-1)(F(k)-k)$, the amount that it is supposed to return to the other non-defaulting borrowers. Now, if $f$ is small, then the MFI may be able to bribe a borrower (in the second group) to default just before she makes her final payment. Finally, under such a scheme, once the first group of borrowers have completed their projects, they are at the mercy of the second group and could be exploited by them. Anticipating this, the borrowers in the first group may be better off defaulting immediately on their loans.

The validity of Proposition 2 also depends on the assumption that the lender is not allowed to cross-subsidize. To see this, consider a project size $k>k^{L}(r)$. Now consider a scheme with two borrowers where both of them obtains the loan immediately. However, the repayment 
obligation is such that borrower 1 only pays a fraction $\alpha$ of her project cost, while the second borrower has to pay $k$, as well as the remaining share $(1-\alpha) k$ of the project cost of the first borrower. By choosing $\alpha$ small enough, one can always ensure that default by the second borrower adversely affect the first borrower. This means that the first borrower will always impose the social sanction. Now if the social sanction $f$ is large, then the threat of this social sanction will ensure that borrower 2 does not default on her loan either.

\subsection{Proof of the claim in footnote 20}

We provide a proof of the claim in footnote 20 , via the following

Lemma. Consider the two-stage group arrangement under complete collusion. If $<n, m, t^{2}, k, y^{i}\left(t^{i}+\right.$ $\tau, k)>$ is feasible, then $k$ can be sustained using IFR schemes.

Proof. Let $P^{G}(t, S)$ denote the aggregate continuation payoff for the group at time $t$ given the scheme $S=<n, m, t^{2}, k, y^{i}\left(t^{i}+\tau, k\right)>$ and let $P^{G}\left(t, S^{\prime}\right)$ denote the aggregate continuation payoff for the group under $S^{\prime}$, where $S^{\prime}$ denotes the scheme $<n, m, t^{2}, k>$ in which a borrower in group $i$ repays according to the IFR corresponding to $k$. It is straightforward to check that $P^{G}(t, S) \leq P^{G}\left(t, S^{\prime}\right)$ for all $t$. Furthermore, letting $D^{G}(t, S)$ and $D^{G}\left(t, S^{\prime}\right)$ denote the aggregate default payoff under the two schemes $S$ and $S^{\prime}$ respectively, it is easy to see that $D^{G}(t, S)=D^{G}\left(t, S^{\prime}\right)$ for any $t$. Therefore, it follows that if $S$ satisfies the ND condition for all $t$, then so must $S^{\prime}$.

\subsection{Proof of the claim for the multi-stage game with limited collusion}

We consider the case where, under limited collusion, the MFI can endogenously decide on the number of stages. We first make a formal claim and then prove it.

Proposition. Consider $f>0$ and $k$ such that $0<k<k^{0}(r)$. Then there exists $n^{*} \geq 2$ such that the project size $k$ is $r$-feasible using an one cyclical multistage lending scheme with $n \geq n^{*}$ borrowers.

Proof. The proof is by construction and goes through even if the integer constraint is taken into account. Fix any $k$ such that $k<k^{0}(r)$, so that $F(k)-k(1+r)>0$. Let $s \geq 1$ be the smallest integer for which $s(F(k)-k(1+r))>k(1+r)$. Given $f>0$, let $m$ be the smallest integer for which we have

$$
b(k)-m f<F(k)-k(1+r),
$$

where $m$ is well-defined since group size $n$ is endogenous. Consider now a group of $n \geq n^{*}$ members where $n^{*}=m(s+1)$. Let $t^{i}, i=0,1, \ldots, s$ be given by

$$
t^{0}=0, t^{1}=\frac{k(1+r)}{s F(k)}, t^{2}=\frac{2 k(1+r)}{s F(k)}, \ldots, t^{s}=\frac{s k(1+r)}{s F(k)} .
$$

The sequential lending scheme operates as follows, at every $t^{i}$, at least $m$ members of the group are advanced a loan of $k$. Moreover, if at any date $t \in\left[0,1+t^{s}\right]$, any borrower defaults on her repayment obligation, the lender liquidates all projects. Moreover, if the default date $t$ is less than $t^{s}$, the lender makes no further loan to the members yet to receive their loans. Finally, the repayment scheme for any borrower is just the IFR corresponding to the investment level $k$. 
We now show that at any date $t \in\left[0,1+t^{s}\right]$, no groups of borrowers have an incentive to default. To show this, it is sufficient to consider the default incentives at dates $t=\left\{0, t^{1}, \ldots, t^{s}\right\}$ and $t=\left\{1,1+t^{1}, 1+t^{2} \ldots, 1+t^{s-1}\right\}$.

The result is clearly true for all $t \in\left\{0, t^{1}, \ldots, t^{s-1}\right\}$. Since default at any such date by any group of borrowers would mean that at least $m$ borrowers will not be granted a loan. Thus, at the minimum, a defaulting borrower will attract a social penalty of $m f$. Because of (30), a defaulting borrower must be strictly worse off.

Consider now the date $t^{s}=\frac{k(1+r)}{F(k)}$ in which the last set of $m$ borrowers receive their loans. Since $t^{s}=\frac{k(1+r)}{F(k)}$, the borrowers who received their loans at $t=0$ have already repaid their loans and thus the continuation payoff of any such borrower is exactly $F(k)\left(1-t^{s}\right)$. The default payoff for such a borrower at this date, however, is $b(k)\left(1-t^{s}\right)$ which is strictly less than $F(k)\left(1-t^{s}\right)$ because of our assumption that $F(k)>b(k)$. Clearly all such borrowers will be adversely affected by any default decision in the group. Consequently, this group of borrowers will necessarily invoke the social sanction on any defaulting borrower. As a result, the maximum payoff to any defaulting borrower at such a date is at most $b(k)-m f$ which by (24) is strictly less than $F(k)-k(1+r)$.

Consider now date $t=1+t^{j}$ for $j<s$. At this date, some of the borrowers have already completed their project and thus, will not invoke the social sanction. We now show that the set of borrowers who got the loan at $t=t^{j+1}$ will be adversely affected by the default decision of any other borrower in the group. To see this note that $\left(1+t^{j}\right)-\left(t^{j+1}-t^{j}\right)=$ $\frac{s F(k)-k(1+r)}{s F(k)}+\frac{j k(1+r)}{s F(k)}>\frac{s F(k)-k(1+r)}{s F(k)}$. This is strictly greater than $\frac{k(1+r)}{F(k)}$ since our choice of $s$ satisfies $s(F(k)-k(1+r))>k(1+r)$. This implies that the group of borrowers receiving their loans at $t=t^{j}$ have already repaid their loans and thus will be adversely affected by the defaulting decision of any other borrower. Consequently, this set of borrowers will impose a sanction of $f$ on any defaulting borrower at $t=1+t^{j}$. Thus, the net payoff of any defaulting borrower is at most $b(k)-m f$ which by (24) is strictly less than $F(k)-k(1+r)$.

\subsection{Proof of the claim for the multi-stage game with complete collusion}

We consider the case where, under complete collusion, the MFI can endogenously decide on the number of stages. We first make a formal claim and then prove it.

Proposition. Consider $0<k<k^{0}(r)$ such that $\phi(k, r)>2$. Then, there is no one cyclical scheme with side payments for which $k$ is feasible.

Proof. An IFR lending scheme $L\left(\left(n^{1}, n^{2}, \ldots, n^{m}\right) ;\left(t^{0}, t^{1}, \ldots, t^{m}\right) ; k\right)$ involves $n=\sum_{j} n^{j}$ borrowers, in which $n^{j}$ borrowers get their loan of $k$ at time $t^{j}, t^{j}<t^{j+1}$. We normalize $t^{0}=0$. Moreover assume that a borrower receiving the loan at time $t^{j}$ has the repayment obligation corresponding to the IFR starting at $t^{j}$. We denote such a scheme by simply $L(n, k)$.

Given any scheme $L(n, k)$ and for any $t$, let $P^{G}(t)$ denote the aggregate continuation payoff of the group assuming that the group never defaults on his loan. Furthermore, at $t$, the payoff of an active borrower who received loan at $t^{j}$ (and is yet to complete his project) has a default payoff of $b(k)\left(1+t^{j}-t\right)$. Thus, at $t$, the aggregate default payoff of the group is given by

$$
D^{G}(t)=\sum_{j \in n(t)} b(k)\left(1+t^{j}-t\right) .
$$


where $n(t)$ is the set of active borrowers at date $t$.

Definition. A lending scheme satisfies the ND constraint at $t$ iff

$$
D^{G}(t) \leq P^{G}(t)
$$

We consider lending schemes that are not too protracted in that the last borrower to obtain a loan does so at a time when the first set of borrower(s) are yet to complete their projects.

Definition. A lending scheme is said to be one-cyclical if $t^{m}<1$.

Definition. A lending schemes is said to have no bunching if for any $t^{i}, t^{i}>0$, exactly one borrower is given the loan.

It is easy to see that if a project of size $k$ is feasible using a group lending arrangement, then $k$ is feasible using a lending scheme that has no bunching. The idea of this is quite straightforward. Considering any feasible scheme that has bunching means that there exists some $t^{i}>0$ such that at least at least two borrowers get their loans at $t^{i}$. Construct now an alternative scheme that is identical to the original scheme, except for the following differences: (a) one of the borrowers bunched at $t^{i}$, now receives her loan at $t^{i}-\epsilon$, where $t^{i-1}<t^{i}-\epsilon<t^{i}$, and (b) all the agents active at $t^{i}$ (i.e. yet to complete their projects), are also active at $t^{i}-\epsilon$. Such an alternative scheme exists. Moreover, in this alternative scheme, there is no change in the default incentives of the group for $t \leq t^{i-1}$, while such incentives are either unchanged, or decreased for $t>t^{i}$. Next consider default incentives at $t^{i}-\epsilon$. While it is true the default incentive of the group is increased because a new borrower is given a loan at an earlier date, $t^{i}-\epsilon$, this increase in default incentive can be made arbitrarily small by choosing $\epsilon$ to be small, on the other hand since a default at $t^{i}-\epsilon$, at least one member in the group (who is supposed to get loan at $t^{i}$ ) will be denied loans, a default at $t^{i}-\epsilon$ leads to a quantum drop in the default payoff of the group. Consequently, in search of a feasible scheme, we can consider schemes in which in a group of $n$ members, $(n-m)$ borrowers receive loan at $t=0$ and the remaining borrowers receive loan at $t^{i}, i=1,2, \ldots m$, where $t^{i} \neq t^{i+1}$.

Lemma *. A necessary condition for supporting a loan of size $k$ in a group of $n$ member where $(n-m)$ receive loan at $t=0$ is

$$
\frac{F(k)-k(1+r)}{b(k)} \geq \frac{2 n-m+1}{4 n-m-1} .
$$

Proof. Denote by $t^{i^{\prime}}=t^{i}-t^{i-1}$, and let $\pi(k ; r)=F(k)-k(1+r)$.

$$
\begin{aligned}
t=t^{1}: b(k)+\left(1-t^{1^{\prime}}\right) b(k)(n-m) & \leq n \pi(k ; r), \\
t=t^{2}: b(k)+b(k)\left(1-t^{2^{\prime}}\right)+b(k)(n-m)\left(1-t^{1^{\prime}}-t^{2^{\prime}}\right) & \leq n \pi(k ; r), \\
\ldots \ldots \ldots \ldots & \ldots \ldots \ldots \ldots . . \\
t=t^{m}: b(k)+b(k)\left(1-t^{m^{\prime}}\right)+\cdots b(k)(n-m)\left(1-t^{1^{\prime}}-t^{m^{\prime}}\right) & \leq n \pi(k ; r), \\
t=1: t^{1^{\prime}} b(k)+\ldots+\left(t^{1^{\prime}}+\ldots+t^{m^{\prime}}\right) b(k) & \leq m \pi(k ; r), \\
\ldots \ldots \ldots & \ldots \ldots \ldots \ldots . \\
t=1+t^{m-1}: t^{m^{\prime}} b(k) & \leq \pi(k ; r) .
\end{aligned}
$$


Note that the above conditions arise out of the ND conditions at $t^{1}, t^{2}, \ldots, t^{m}, 1,1+t^{1}, \cdots, 1+$ $t^{m-1}$. At $t=t^{1}$, for example, this necessary condition coincides with the ND constraint at $t^{1}$ if the first $n-m$ borrowers are still repaying their loans at $t^{1}$. Otherwise, the corresponding ND yields $b(k)+b(k)(n-m)\left(1-t^{1^{\prime}}\right) \leq m \pi(k ; r)+(n-m) F(k)\left(1-t^{1^{\prime}}\right)$, which yields the same necessary condition (given that the borrower has already repaid). The other necessary conditions follow a similar logic.

Multiplying the inequality at $t=1$ by $(n-m)$ and summing this with all the other inequalities yields:

$$
b(k)+2 b(k)+\cdots+b(k) m+(n-m) b(k) m \leq \pi(k ; r)[n m+1+\cdots+(m-1)+m(n-m)],
$$

i.e.

$$
\frac{b(k) m(2 n-m+1)}{2} \leq \frac{\pi(k ; r)) m(4 n-m-1)}{2} .
$$

We are finally in a position to prove the proposition.

Proof. We begin by showing that a necessary condition for a one-cyclical scheme $L(n, k)$ to be feasible is that $\frac{F(k)-k(1+r)}{b(k)} \geq \frac{n+2}{3 n}$. Note that $\frac{d}{d m}\left[\frac{2 n-m+1}{4 n-m-1}\right]<0$. Thus if there is a lending scheme $L(n, k)$ that satisfies the necessary conditions of the Lemma, then there is fully sequential scheme which satisfies the necessary condition $\frac{F(k)-k(1+r)}{b(k)} \geq \frac{n+2}{3 n}$. The result now follows since $\frac{n+2}{3 n}$ is decreasing in $n$, and $\lim _{n \rightarrow \infty} \frac{n+2}{3 n}=\frac{1}{3}$.

\subsection{Optimal $(k, r)$ under Complete Collusion}

Here, we briefly indicate how to solve for the optimal contracts in the presence of complete collusion. In what follows, we ignore any integer constraint on $n$ and assume instead that given $r$, a project of size $k$ is $r$-feasible as long as $k \leq k^{C}(r)$ (see footnote 21 in the text). The lender's optimization problem can then be written as

$$
\max _{k, r}[(r-c) k+\beta \pi(k, r)]
$$

subject to the following incentive constraints:

$$
\begin{aligned}
\frac{\pi(k, r)}{b(k)}-\phi(k, r) & \geq 0, \\
\frac{k(1+r)}{F(k)}-\phi(k, r) & \geq 0 .
\end{aligned}
$$

It is straightforward to check that at the optimal solution, one (or possibly both) of the constraints must bind and thus $\phi(k, r)$ must be strictly positive. To show that at the optimal choice, the project size is strictly greater than $k_{I}$, one can proceed as follows. Fix any $r$ and consider the choice of optimal project size $k$. Since $r$ is fixed, at the optimal, it follows that the first constraint will bind if $k_{1}(r)<k_{2}(r)$ (where recall that $k_{1}(r)$ and $k_{2}(r)$ satisfy

$$
\phi\left(k_{1}(r), r\right)=\frac{\pi\left(k_{1}(r), r\right)}{b\left(k_{1}(r)\right)} ; \quad \text { and } \quad \phi\left(k_{2}(r), r\right)=\frac{k_{2}(r)(1+r)}{F\left(k_{2}(r)\right)},
$$

respectively), while the second constraint will bind otherwise. 
First, let $k_{1}(r) \leq k_{2}(r)$. In this case, we have $\phi(k, r)=\frac{\pi(k, r)}{b(k)}$. Simplifying and rearranging terms, we get $\pi(k, r)^{2}+b(k) \pi(k, r)-b(k)^{2}=0$. This gives us $\pi(k, r)=\frac{-b(k)+\sqrt{(b(k))^{2}+4(b(k))^{2}}}{2}$, or that

$$
\pi(k, r)=\frac{b(k)(\sqrt{5}-1)}{2} .
$$

Using the above equation, we get $(r-c) k=F(k)-k(1+c)-\frac{b(k)(\sqrt{5}-1)}{2}$. Thus the per borrower payoff to the lender can be written as $F(k)-k(1+c)-\frac{(1-\beta) b(k)(\sqrt{5}-1)}{2}$. The first order condition for the choice of $k$ then is given by

$$
F^{\prime}(k)-(1+c)-\frac{(1-\beta) b^{\prime}(k)(\sqrt{5}-1)}{2}=0 .
$$

Since $\frac{\sqrt{5}-1}{2}<1$, it follows by comparing this with the first order condition for $k_{I}$ (see equation (18) in the text) that the optimal choice of $k$ must be strictly greater than $k_{I}$.

Now assume that $k_{1}(r)>k_{2}(r)$. In this case, the second constraint must bind, i.e, $\phi(k, r)=$ $\frac{k(1+r)}{F(k)}$. Using the definition of $\phi(k, r)$ and simplifying, we then get $\frac{b(k)}{1+\alpha(k, r)}=\pi(k, r)$ where $\alpha(k, r)=\frac{k(1+r)}{F(k)}$. This gives us $(r-c) k=F(k)-k(1+c)-\frac{b(k)}{1+\alpha(k, r)}$. Using this information, the per borrower lender's payoff can be written as $F(k)-k(1+c)-(1-\beta) \frac{b(k)}{1+\alpha(k, r)}$. For any $r$, the project choice $k$ must then satisfy

$$
F^{\prime}(k)-(1+c)-(1-\beta) \frac{b^{\prime}(k)}{1+\alpha(k, r)}+(1-\beta) b(k) z(k, r)=0,
$$

where $z(k)=\left[\frac{\partial \alpha(k, r)}{\partial k}\right]\left[\frac{1}{(1+\alpha(k, r))^{2}}\right]>0$. Thus, for any $r$, at the optimal choice of $k$, we must have

$$
F^{\prime}(k)-(1+c)-(1-\beta) b^{\prime}(k)<0 .
$$

Since $k_{I}$ satisfies $F^{\prime}\left(k_{I}\right)-(1+c)-(1-\beta) b^{\prime}\left(k_{I}\right)=0$, by A.2, it follows that the optimal project size under group lending with complete collusion must be strictly greater than $k_{I}$. This follows since, given that the first order maximization conditions under both lending schemes are independent of $r$, and that we have shown the result for arbitrary $r$, the result must be true at optimal choice of $r$ as well.

The preceding arguments suggest that, in general, it will be extremely complicated to get a simple closed form solution for the equilibrium. Consequently the comparative statics results for this model will not be easy to derive.

\subsection{Proof of Remark 9}

Here we state and prove a version of Proposition 3, where $n$ can be chosen by the MFI and the integer constraint is respected. For ease of exposition, we provide the proof for $r=0$. The proof for $r>0$ is completely analogous.

Proposition $3^{*}$ Consider project size $k$, such that $0<k<k^{0}$. Then, under a two stage arrangement with side transfers:

(i) [Necessity] if $k$ is feasible, then $k \leq k^{C}$, and

(ii) [Sufficiency] if $k<k^{C}$, then $k$ is feasible using a two stage group lending arrangement. 
Proof. (i) Necessity: If $k$ is feasible, then from equation (19) in the text, it follows that $\phi(k) \leq \min \left\{\frac{k}{F(k)}, \frac{F(k)-k}{b(k)}\right\}$. From Lemma 5 , it then follows that $k \leq k^{C}$.

(ii) Sufficiency: Suppose $k<k^{C}$. If $k \leq k^{I}$, then a group consisting of $n$ borrowers, $n \geq 1$, in which all borrowers are given the loan $k$ at $t=0$ is feasible. Therefore, assume that $k>k^{I}$. We now construct a feasible group lending arrangement that involves $k$.

Since $k<k^{C}$, by Lemma $5, \phi(k)<\min \left\{\frac{k}{F(k)}, \frac{F(k)-k}{b(k)}\right\}$.

For any $\epsilon>0$, let $\frac{b(k)}{F(k)-k}+\epsilon$ be a rational number. Since rational numbers are dense in reals, it follows that one can choose an $\epsilon$ that is arbitrarily close to zero. ${ }^{41}$ Given such a choice of $\epsilon$, consider a pair of positive integers $(n, m)^{42}$ such that

$$
\frac{b(k)}{F(k)-k}+\epsilon=\frac{n}{n-m} .
$$

Since $k>k^{I}$, we have $\frac{b(k)}{F(k)-k}>1$ and thus $m>0$ and $n>m$.

Consider now a group consisting of $n$ members of whom $(n-m)$ are given a loan of size $k$ at $t=0$, and $m$ receive their loans of $k$ later. By construction of $(n, m)$, the no default condition at $t=0$ is given by

$$
(n-m) b(k) \leq n[F(k)-k]
$$

which is satisfied because of equation (32) and the fact that $\epsilon>0$.

Let the remaining $m$ members of the group be given the loan at $t^{2}(\epsilon)$, where $t^{2}(\epsilon)$ satisfies

$$
n[b(k)-(F(k)-k)]=(n-m) b(k) t^{2}(\epsilon) .
$$

Dividing through by $(n-m) b(k)$, we have that

$$
t^{2}(\epsilon)=\frac{n}{n-m}\left[1-\frac{F(k)-k}{b(k)}\right]=\left[\frac{b(k)}{F(k)-k}+\epsilon\right]\left[1-\frac{F(k)-k}{b(k)}\right],
$$

where the last equality follows from (32). Simplifying and recalling that $\phi(k)=\frac{b(k)}{F(k)-k}-1$, the above equation can be rewritten as

$$
\phi(k)+\epsilon\left[1-\frac{F(k)-k}{b(k)}\right]=t^{2}(\epsilon) .
$$

It follows that for $\epsilon$ close to zero, $t^{2}(\epsilon)$ is arbitrarily close to $\phi(k)$. Since $\phi(k)<\frac{k}{F(k)}$, it then follows that one can choose $\epsilon$ sufficiently small such that $t^{2}(\epsilon)<\frac{k}{F(k)}$. Given that the repayment scheme is an IFR, it follows that at $t^{2}(\epsilon)$, the $(n-m)$ members in the first group are yet to meet their repayment obligations (as $t^{2}(\epsilon)<k / F(k)$ ). Thus the continuation payoff for the entire group at $t^{2}(\epsilon)$ equals $n[F(k)-k]$ and the no default condition at $t=t^{2}(\epsilon)$ is given by

$$
(n-m) b(k)\left(1-t^{2}(\epsilon)\right)+m b(k) \leq n[F(k)-k] .
$$

Re-arranging, the preceding equation becomes $(n-m) b(k)+m b(k)-n[F(k)-k] \leq t^{2}(\epsilon)(n-$ $m) b(k)$, which simplifies to $n[b(k)-(F(k)-k)] \leq t^{2}(\epsilon)(n-m) b(k)$, i.e. $t^{2}(\epsilon) \geq \frac{n}{n-m}\left[1-\frac{F(k)-k}{b(k)}\right]$. This is satisfied with an equality by the construction of $t^{2}(\epsilon)$.

\footnotetext{
${ }^{41}$ Indeed, when $\frac{b(k)}{F(k)-k}$ is a rational number itself, one can choose $\epsilon$ to be zero.

${ }^{42} n$ and $m$ depend on $\epsilon$ but we drop this dependence for notational simplicity.
} 
Finally, consider $t=1$. If the second group members have already repaid their loan by this date, then there is nothing more to prove. Otherwise, the loan is yet to be repaid and thus the continuation payoff of the group equals $m[F(k)-k]$. Finally recall that $\phi(k)<\frac{F(k)-k}{b(k)}$. Consequently since from (33), $t^{2}(\epsilon)$ is arbitrarily close to $\phi(k)$ for $\epsilon$ small enough, from continuity it follows that $t^{2}(\epsilon)<\frac{F(k)-k}{b(k)}$ for $\epsilon$ small enough. Thus the no default condition is satisfied at $t=1$ as well.

Acknowledgements. We would like to thank participants at the 4th CEDI conference at Brunel University (2009), the Growth and Development Conference (2010) at the Indian Statistical Institute, as well as seminar participants at Monash University, Nanyang Technological University, Singapore Management University, University of Sydney and University of Western Sydney, for their comments. The second author would also like to thank the University of Sydney, Monash University, as well as the PPRU, ISI Delhi (grant No. PPRU870-G), for support. We would also like to thank Maitreesh Ghatak, as well as several anonymous referees for their very helpful comments.

\section{Reference}

Abbink, K., Irlenebusch, B., Renner, E., 2006. Group size and social ties in micro-finance institutions. Economic Enquiry 44, 614-628.

Aghion, B.A., 1999. On the design of a credit agreement with peer monitoring, Journal of Development Economics 60, 79-104.

Aghion, B.A., Gollier, C., 2000. Peer group formation in an adverse selection model, Economic Journal 110, 632-43.

Aghion, B.A., Morduch, J., 2005. The Economics of Micro-finance. The MIT Press, Cambridge, Massachusetts, London, England.

Ahlin, C., Townsend, R., 2007. Using repayment data to test across models of joint liability lending. Economic Journal 117, F11-F51.

Ahlin, C., Waters, B., 2011. Dynamic lending with comparison to group-lending in the Ghatak/Stiglitz/Weiss adverse selection model.

Available at: http://econ.msu.eduseminars/docs/dynamicSWG.pdf

Albuquerque, R., Hopenhayn, H., 2004. Optimal lending contracts and firm dynamics, Review of Economic Studies 7, 285-315.

Aniket, K., 2006. Sequential group lending with moral hazard. Edinburgh School of Economics. Discussion Paper No. 136.

Aniket, K., 2009. Queuing for credit: Increasing the reach of microfinance through sequential group lending, Working Paper.

Available at: http://www.aniket.co.uk/research/sql-EJ.pdf

ASA. 2008. Annual Report 2007. Dhaka.

Banerjee, A., Besley, T., Guinnane, T.W., 1994. Thy neighbor's keeper: the design of a credit cooperative with theory and a test. Quarterly Journal of Economics 109, 491-515.

Bauer, M., Chytilova, J., Morduch, J., 2008. Behavioral foundations of microcredit: experimental and survey evidence from rural India. Mimeo. New York University.

Besley, T., Coate, S., Loury, G., 1993. The economics of rotating savings and credit associations. American Economic Review 83, 792-810. 
Besley, T., Coate, S., 1995. Group lending, repayment schemes and social collateral. Journal of Development Economics 46, 1-18.

Besley, T., Ghatak, M., 2005. Competition and incentives with socially motivated agents. American Economic Review 95, 616 - 636.

Besley, T., Ghatak, M. 2006. Sorting with socially motivated agents: implications for school competition and teacher incentives. Journal of the European Economic Association 4, 404-414.

Bhole, B., Ogden, S., 2010. Group lending and individual lending with strategic default. Journal of Development Economics 91, 348-363.

Bond, P., Rai, A., 2009. Borrower runs. Journal of Development Economics 88, 185-191.

Castri, S.d., 2010. Micro-credit sector in Italy: small initiatives in a dynamic scenario, in: Carboni, B.J., Calderon, M.L., Garriola, S.P., Dyson, K., Kickul, J. (Eds.), "Handbook of Micro-Credit in Europe: Social Inclusion Through Microenterprise Development. Edward Elgar, UK, pp.61-100.

Christen, R., Rosenberg, R. and Jayadeva, V. 2004. Financial institutions with a double bottom line: implications for the future of microfinance. CGAP Occasional Papers, July.

Chowdhury, S., Roy Chowdhury, P., and Sengupta, K., 2009. Gradual Repayment with Sequential Financing in Micro-finance. Mimeo.

Conning, J., 1999. Outreach, sustainability and leverage in monitored and peer-monitored lending, Journal of Development Economics 60, 51-77.

Conning, J., 2005. Monitoring by delegates or by peers? Joint liability loans under moral hazard. Hunter College, Department of Economics, Working Paper 407.

De Quidt, J., Fetzer, T., Ghatak, M., 2012. Market Structure and Borrower Welfare in Microfinance. Centre for Economic Policy Research DP 9165, http://dev3.cepr.org/pubs/newdps/dpslist.asp?dpno $=9165$.

Fafchamps, M., Lund, S., 2003. Risk-sharing networks in rural Philippines. Journal of Development Economics 71(2), 261-287.

Fehr, E., Schmidt, K.M., 1999. A theory of fairness, competition and cooperation. Quarterly Journal of Economics 114, 817-868.

Feijenberg, B., Field, E., Pande, R. 2011. The economic returns to social interaction: Experimental evidence from micro-finance (forthcoming, Review of Economic Studies).

Field, E., Pande, R., Papp, J., Rigol, N., 2010. Term structure of debt and entrepreneurship behaviour: Experimental evidence from micro-finance. Mimeo. Harvard University.

Field, E., Pande, R., 2008. Repayment frequency and default in micro-finance: evidence from India. Journal of European Economic Association 6, 501-505.

Fischer, G., Ghatak, M., 2010. Repayment frequency in microfinance contracts with presentbiased borrowers. Mimeo, London School of Economics.

Fischer, G., Ghatak, M., 2011. Spanning the Chasm: Uniting Theory and Empirics in Microfinance Research, in: Armendiariz, B., and Labie, M. (Eds.) Handbook of Microfinance, World Scientific.

Ghatak, M., 1999. Group lending, local information and peer selection. Journal of Development Economics 60, 27-50.

Ghatak, M., 2000. Screening by the company you keep: Joint liability lending and the peer selection effect. Economic Journal 110, 601-631.

Ghatak, M., Guinnane, T.W., 1999. The economics of lending with joint liability: theory and practice. Journal of Development Economics 60, 195-228. 
Gine, X., Karlan, D., 2010. Group versus individual liability: Long term evidence from Philippine Microcredit lending groups. Mimeo.

Gine, X., Krishnaswamy, K., and Ponce, A., 2011. Strategic default in joint liability groups: Evidence from a naturel experiment in India. Mimeo.

Gintis, H., Bowles, S., Boyd, R., Fehr, E., 2005. Moral sentiments and material interests: origin, evidence and consequences. In: Gintis, H., Bowles, S., Boyd, R., Fehr, E. (Eds.) Moral sentiments and material interests: the foundations of cooperation in economic life. Cambridge, MIT.

Guha, B., Roy Chowdhury, P., 2013. Micro-finance competition: Motivated micro-lenders, double-dipping and default. Journal of Development Economics 105, 83-105.

Gomez, R., Santor, E., 2003. Do peer group members outperform individual borrowers? A test of peer group lending using Canadian micro-credit data. Bank of Canada WP 2003-33, October.

Hossein, M., 1988. Credit for the alleviation of rural poverty: the Grameen Bank in Bangladesh. Research Report 65, IFPRI, February.

Jain, S., Mansuri, G., 2003. A little at a time: the use of regularly scheduled repayments in microfinance programs. Journal of Development Economics 72, 253-279.

Karlan, D. , 2007. Social connections and group banking, Economic Journal 117, F52-F84.

Kurosaki, T., Khan, H.U., 2009. Vulnerability of microfinance to strategic default and covariate shocks: evidence from Pakistan. Mimeo. Hitotsubashi University.

Laffont, J.J., N'Guessan, T.T., 2000. Group lending with adverse selection. European Economic Review 44, 773-784.

Laffont, J.J., Rey, P., 2003. Moral hazard, collusion and group lending. IDEI Working Papers, IDEI, Toulouse.

Malegam, Y.H., 2011. Report of the Sub-committee of the Central Board of Directors of Reserve Bank of India to Study Issues and Concerns in the MFI Sector. Reserve Bank of India (January 2011).

Molnar, G., 2010. A new approach to deliver micro-credit to Roma population, Conference on Micro-finance in Europe, 2010,

Available at: http://ee.europa.eu/social/Blobservelet?docid=6297\&langid=en

Morduch, J., 1999. The micro-finance promise. Journal of Economic Literature 37, 15691614.

Paal, B., Wiseman, T., 2011. Group insurance and lending with endogenous social collateral. Journal of Development Economics 94, 30-40.

Rai, A., Sjostrom, T., 2004. Is Grameen Lending efficient? Repayment incentives and insurance in village economies. Review of Economic Studies 71, 217-234.

Rai, A., Sjostrom, T., 2010. Redesigning micro-finance, Mimeo, Rutgers University.

Roy Chowdhury, P., 2005. Group-lending: sequential financing, lender monitoring and joint liability. Journal of Development Economics 77, 415-439.

Roy Chowdhury, P., 2007. Group-lending with sequential financing, contingent renewal and social capital. Journal of Development Economics 84, 487-506.

Sadoulet, L., 2000. The role of mutual insurance in group-lending. ECARES/ Free University of Brussels Working Paper.

Shapiro, D., 2012. Microfinance and dynamic incentives. Mimeo, University of North Carolina Charlotte. 
Sinn, M., 2009. Sequential Lending: A mechanism to raise repayment rates in group lending? Mimeo, London School of Economics.

Srinivasan, N., 2009. Microfinance India, State of the Sector Report 2009. Sage India.

Stiglitz, J., 1990. Peer monitoring and credit markets. World Bank Economic Review 4, 351-366.

Townsend, R., 1994. Risk and insurance in village India. Econometrica 62, 539-591.

Udry, C., 1990. Credit markets in Northern Nigeria: credit as insurance in a rural economy. World Bank Economic Review 4, 251-269.

United Nations Interagency Committee on Integrated Rural Development for Asia and the Pacific. Partners in rural poverty alleviation: NGO cooperation. United Nations, New York; 1992.

Van Tassel, E., 1999. Group lending under asymmetric information. Journal of Development Economics 60, 3-25.

Varian, H., 1990. Monitoring agents with other agents. Journal of Institutional and Theoretical Economics 146, 153-174.

Wenner, M., 1995. Group credit: A means to improve information transfer and loan repayment performance. Journal of Development Studies 32, 263-281.

Wydick, B., 1999. Can social cohesion be harnessed to repair market failure? Evidence from group lending in Guatemala. Economic Journal 109, 463-475.

Zeller, M., Sharma, M., Ahmed, A., 1996. Credit for the rural poor: country case Bangladesh. IFPRI, Washington, DC. 